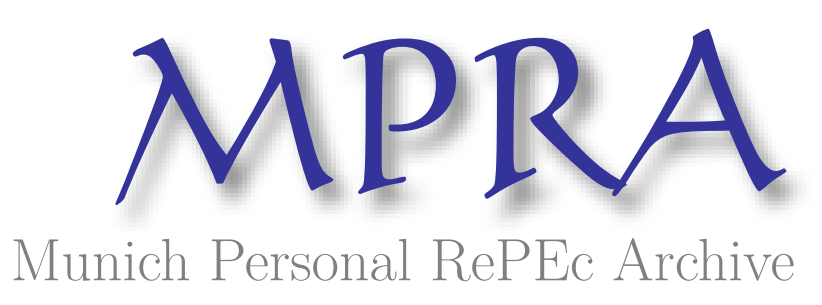

\title{
Hidden Schooling: Repeated Grades and the Returns to Education and Experience
}

Kennedy, Kendall

Mississippi State University

31 October 2018

Online at https://mpra.ub.uni-muenchen.de/90454/

MPRA Paper No. 90454, posted 14 Dec 2018 11:30 UTC 


\title{
Hidden Schooling: Repeated Grades and the Returns to Education and Experience
}

\author{
Kendall J. Kennedy*
}

October 31, 2018

\begin{abstract}
Over the past four decades, nearly $25 \%$ of all American public school students repeated at least one grade in primary or secondary school, and ninth grade repeating increased four-fold. Despite its prevalence, few economists have attempted to account for grade repeating when estimating the returns to education and experience. I show that $10 \%$ of the increase in ninth grade repeating was caused by changes in compulsory schooling laws (CSLs). Because CSLs increase both grade repeating and educational attainment, compulsory education-based IV estimates of the returns to education are positively biased by up to $38 \%$. Additionally, grade repeating causes endogenous measurement error in labor market experience. Solely through this measurement error, I show that the residual black-white wage gap is overstated by $10 \%$, the wage return to a high school diploma is overstated by $11 \%$ relative to dropouts, and the labor supply gap between dropouts and high school graduates is overstated by $23 \%$. Controlling for age instead of experience reduces this bias, suggesting age should be a standard control variable for reduced-form analysis, not experience.
\end{abstract}

*kkennedy@business.msstate.edu; The author thanks Philip Oreopoulos for providing a list of compulsory schooling laws in the United States. This research was conducted with restricted access to Bureau of Labor Statistics (BLS) data. The views expressed here do not necessarily reflect the views of the BLS. 


\section{Introduction}

Grade repeating in elementary and secondary school is surprisingly common in the United States; the NLSY97 reports that $23 \%$ of Americans born in the early 1980s repeated at least one grade at some point in their academic career. Even more surprising is which grades are being repeated. 50 years ago, grade repeating was almost exclusive to Kindergarten and the 1st grade, but from the 1980s to today, researchers (Haney et al., 2004; Heubert and Hauser, 1998; Planty et al., 2009) estimate the annual 9th grade retention rate at between 5 and $15 \%$ per year in each year.

This sudden rise in 9th grade retention has largely been ignored by the economics literature, but its effects are potentially quite problematic. 9th grade retention, and grade retention in general, is unobserved in many popular microdata sets, and not reported by default in any popular microdata set. This means that estimation of the returns to education is incomplete, omitting any effects of repeated grades. Instrumental variables estimation using compulsory schooling instruments is particularly affected by this issue, as compulsory schooling laws are one of the primary causes behind the rise in 9th grade repeating. In addition, the typical measures of labor market experience face large and potentially endogenous measurement error when failing to account for grade repeating in any grade. The most common measure of labor market experience is a simple proxy, Age - Educational Attainment - 6 . For grade repeaters, however, this measure does not correctly state the number of years a person has been out of school, because educational attainment does not include repeated grades. Thus, failure to account for repeated grades in calculating experience can create bias in other estimates, if repeating rates are correlated with the variable of interest.

In this study, I examine how repeated grades, particularly in the 9th grade, affect estimation when controlling for educational attainment and labor market experience, even when education and experience are not of primary interest to the researcher. I show that 
instrumental variables estimates using quarter of birth and/or compulsory schooling law instruments are biased by up to $38 \%$ when failing to account for 9 th grade repeating. Furthermore, I show that estimates of the residual black-white wage gap are overstated by $10 \%$ when failing to account for repeated grades in the measure of labor market experience. The wage gap between GED recipients and high school graduates is overstated by $18 \%$ and the employment gap is overstated by $34 \%$ when failing to account for repeated grades.

I first construct a set of 9 th grade repeating rate estimates using state-level enrollment data from the National Center for Education Statistics (NCES), and compare these estimates to administrative data on repeating rates, as well as to another potential repeating rate estimate from the Current Population Survey (CPS) October Supplement. I then move to an examination of compulsory schooling laws. Compulsory schooling laws (CSLs) have been both directly (Acemoglu and Angrist, 2000; Lochner and Moretti, 2004) and indirectly (e.g. quarter of birth as in Angrist and Krueger 1991) used as exogenous sources of variation in estimating the returns to education. I demonstrate that increases in CSLs from 1965 to 2014 caused a 0.7 percentage point increase in the annual 9th grade retention rate; changes in CSLs are responsible for approximately $11 \%$ of 9 th grade retention in the United States over the past 50 years.

Since 9th grade retention is closely tied to educational attainment, omission of 9th grade retention from IV estimation of the returns to education can cause substantial selection bias. Using the Children of the National Longitudinal Survey of Youth 1979 (CNLSY), I examine the interactions between compulsory schooling and 9th grade repeating in IV estimation of the private returns to education. Using only CSLs as instruments causes an $8 \%$ positive bias in the wage return to education, but using quarter of birth instruments causes a $38 \%$ positive bias in the wage return to education. Moreover, these are lower bounds for the selection bias caused by failing to account for endogenous 9 th grade repeating, as weak instruments cause 
upward bias in the corrected IV estimates.

Education and experience are two of the most popular controls in studies using individuallevel data, but both of these are mismeasured in the presence of repeated grades and can introduce considerable bias. By default, nearly all popular datasets define "Education" as educational attainment, which is the highest level of education an individual completed. ${ }^{1}$ Failing to account for repeated grades in measurement of education has the potential to create bias if repeated grades have a non-zero return. More concerning, however, is the measurement of experience; typically, experience is replaced by a proxy "Potential Experience" variable, calculated as Age-Educational Attainment - 6. ${ }^{2}$ This experience measure overstates the true level of "potential experience" for grade repeaters, meaning that if the primary variable of interest is correlated with grade repeating, the inclusion of "potential experience" as a control introduces endogeneity into the model.

Using the NLSY97, I estimate the bias caused by mismeasurement of potential labor market experience in two areas of interest - estimation of the residual black-white wage gap (as in Bound and Freeman 1992) and estimation of the returns to a GED (as in Cameron and Heckman 1993). Black students are 2.5 times as likely as white students to repeat grades; I show that for early career male workers, the residual black-white wage gap is overstated by $10 \%$ when failing to account for repeated grades. GED recipients are 3.5 times as likely as high school graduates to repeat grades; I show that the wage return to a GED is understated by $18 \%$, relative to a high school diploma, and the employment gap, measured by annual hours worked, for GED recipients is overstated by 34\%, relative to a high school diploma when failing to account for repeated grades.

\footnotetext{
${ }^{1}$ The US Census, the American Community Survey (ACS), the Current Population Survey (CPS), the National Longitudinal Survey of Youth (NLSY), the Panel Study of Income Dynamics (PSID), and many others report educational attainment as the default education variable.

${ }^{2}$ When actual labor market experience is observed, researchers conventionally still use this potential experience proxy. Observed labor market experience (e.g. lifetime weeks worked) is highly endogenous, as it is directly caused by labor force participation and employment decisions. (Eckstein and Wolpin, 1989)
} 
These findings have wide-reaching implications. 9th grade repeating is endogenous with compulsory schooling instruments, suggesting a need to revisit previous IV estimation of the returns of education, both for labor market outcomes such as wages and employment and for non-labor market outcomes such as crime and health. Studies controlling for education, and particularly for experience, need to be cognizant of the prevalence of grade repeating in the United States. The typical measure of experience used in the economics literature faces substantial measurement error, that has an incredibly high potential to introduce endogeneity.

The remainder of the paper proceeds as follows. Section 2 explains how repeated grades bias estimation of the returns to education and experience. Section 3 discusses the data sources used in this study. Section 4 describes the construction of estimates and presents stylized facts for the 9 th grade repeating rate over the past 50 years. Section 5 presents theory and results regarding 9th grade repeating and compulsory schooling instruments. Section 6 presents results from estimation of the residual black-white wage gap and returns to the GED using a corrected measure of potential labor market experience, and provides a discussion of potential solutions to mismeasurement of labor market experience. Section 7 provides concluding remarks.

\section{Repeated Grades Bias}

\subsection{Compulsory Schooling as Instrumental Variables}

Compuslory schooling laws are generally considered an exogenous source of variation for educational attainment, making them a prime candidate for instrumental variables estimation of the returns to education. Acemoglu and Angrist (2000) use years of compulsory schooling, calculated as the minimum dropout age minus the mandatory school entry age, as 
an IV in the estimation of the private and external wage returns to education. In addition, they use quarter of birth as an alternate set of instruments, similar to Angrist and Krueger (1991), which operate on the same margin; both CSLs and quarter of birth affect the age and grade at which a teenager can legally drop out of school. A teenager facing a minimum dropout age of 16 would historically be expected to drop out around the 10th grade; depending on their quarter of birth, this teenager may drop out before, during, or after the 10th grade. Both of the aforementioned studies estimated the effects of education on wages; other studies have used CSLs as instruments in estimating the effects of education on crime (Lochner and Moretti, 2004), health and happiness (Oreopoulos, 2007a), employment and poverty status (Oreopoulos, 2007b), and many other outcomes.

9th grade repeating causes two issues with the IV estimate of the returns to education: first, the IV's effect on educational attainment is weakened by 9th grade repeating. CSLs may not cause 9th grade repeaters to increase their educational attainment; they instead repeat the 9 th grade, meaning that CSLs are more likely to face weak instrument bias in the presence of 9 th grade repeating. Second, and more concerning, if there is any return to repeating the 9 th grade, CSLs are invalid instruments. To illustrate this, consider the following simple form of a 2SLS estimation of the returns to education:

$$
\begin{gathered}
\text { Ed Attainment } i=\alpha_{0}+\alpha_{1} C S L_{i}+\lambda X_{i}+u_{i} \\
Y_{i}=\beta_{0}+\beta_{1} \text { Ed Attainment } \\
i
\end{gathered}
$$

If 9th grade repeating has an effect on the outcome $Y_{i}$ and is endogenous with CSLs, then the correct regression model is instead: 


$$
\begin{gathered}
\text { Ed } \text { Attainment }_{i}=\alpha_{0}+\alpha_{1} C S L_{i}+\lambda X_{i}+u_{i} \\
\text { Repeat } 9 \text { th }_{i}=\delta_{0}+\delta_{1} C S L_{i}+\Omega X_{i}+v_{i} \\
Y_{i}=\beta_{0}+\beta_{1} \text { Ed } \widehat{\text { Attainment }}+\beta_{2} \text { Repeat } 9 t_{i}+\Gamma X_{i}+\varepsilon_{i}
\end{gathered}
$$

If the IV is exogenous to 9th grade repeating, then 2SLS estimation of equations 1 and 2 will return a consistent estimate of the return to educational attainment, even if 9th grade repeating has a return to the outcome being tested. However, in Section 5.1 I demonstrate that changes in compulsory education cause a 0.7 percentage point increase in 9th grade repeating. This may appear to be a small change, but the 1st stage regression in equation 1 typically returns an estimate in the range of 0.07 to 0.1 . This suggests that no more than $7-10 \%$ of the population increases their educational attainment as a result of CSLs, and that the effect on 9th grade repeating is within an order of magnitude of the effect on educational

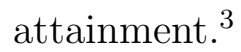

In IV estimation, the bias caused by omission of an endogenous variable has the potential to be quite large, particularly if the 1st stage estimate is weak or small. The IV estimate of the returns to education in the presence of endogenous 9th grade repeating, as in equations 1 and 2, can be expressed as:

$$
\hat{\beta}_{1}^{I V}=\frac{\frac{\widehat{d Y}}{d C S L}}{\frac{d E d \text { Attainment }}{d C S L}} \stackrel{p}{\longrightarrow} \frac{\beta_{1} \frac{d E d \text { Attainment }}{d C S L}+\beta_{2} \frac{d \text { Repeat } 9 \text { th }}{d C S L}}{\frac{d E d \text { Attainment }}{d C S L}}=\frac{\beta_{1} * \alpha_{1}+\beta_{2} \frac{d \text { Repeat9th }}{d C S L}}{\alpha_{1}}
$$

Equation 5 provides a clear illustration of the selection bias caused by 9th grade repeating; given that the 1 st stage point estimate $\hat{\alpha}_{1}$ is only between 0.07 and 0.1 , even a small effect

\footnotetext{
${ }^{3} \mathrm{~A}$ smaller percentage of the population increases their educational attainment due to CSLs if some increase their attainment by more than 1 grade.
} 
of repeating the 9 th grade $\left(\beta_{2}\right)$ would cause massive selection bias - 10-14 times as large as $\beta_{2} \times \frac{d \text { Repeat } 9 t h}{d C S L}$. This bias is entirely unique from the typical concerns with CSLs as IVs - that they are weak instruments (Bound et al., 1995) and that they are only estimating a local average treatment effect (LATE) (Imbens and Angrist, 1994). Instead, 9th grade repeating causes selection bias due to the CSL instrument being endogenous in the second stage regression. In Section $4 \mathrm{I}$ show that 9 th grade repeating did not become prevalent until the mid-1980s. Thus, this is less of a concern for studies using older data. However, any modern study is susceptible to CSLs being invalid instruments.

\subsection{Repeated Grades and Potential Labor Market Experience}

Repeating any grade, not just the 9th grade, can cause severe, endogenous measurement error in estimating the returns to experience. Labor market experience, strictly defined, should be measured as the lifetime number of hours or weeks worked. However, this measure is highly endogenous, as selection into labor force participation and employment is correlated with numerous unobservable characteristics (e.g. Eckstein and Wolpin 1989). Most economic studies are not interested in a precise estimate of the returns to experience, instead wishing to control for potential endogeneity of labor market experience with the other variables of interest in the model. To control for experience without introducing the selection bias from labor force participation and employment, conventionally researchers use a "potential experience" proxy variable, calculated as Age - Educational Attainment - 6 .

The intuition behind this potential experience proxy is readily apparent. An individual's potential labor market experience is the number of years of their adult life that they have not been in school; a 30 year old college graduate has $30-16-6=8$ years of potential labor market experience, while a 30 year old high school graduate has $30-12-6=12$ years of potential labor market experience. However, in the presence of repeated grades, this intuition fails. A 30 year old high school graduate who repeated a grade is measured 
as having 12 years of potential labor market experience, but in reality they only have 11 years of their adult life that they were not in school, having graduated from high school a year later than their peers. ${ }^{4}$ If grade repeating is correlated with the variable of interest, then measurement error in this potential experience proxy variable biases the primary estimate of interest, as labor market experience is systematically overstated for grade repeaters.

\section{Data}

\subsection{Aggregate Repeating Rate Analysis}

I compile a dataset of state-level 9 th grade retention rates for analyzing recent trends in repeating and for demonstrating the endogeneity of compulsory schooling laws with 9th grade repeating. For this, my main data source is the National Center for Education Statistics' (NCES) Annual Reports Program Historical Tables on elementary and secondary enrollment. This provides enrollment counts in each grade, Kindergarten to 12th grade, from 1965 to 2003. I link this with the NCES's Elementary/Secondary Information System (ELSi) from 2003 to 2014 to form a complete panel of state-level enrollment by grade from the 1965-66 school year to the 2013-14 school year. For analysis on compulsory schooling, I use a list of compuslory schooling law changes from 1965 to 2005 from Oreopoulos (2006). This is combined with changes from 2003-2014 taken from Mackey and Duncan (2013), and verified with information from The Education Commission of the States.

Data directly measuring repeating rates are generally nonexistent. However, there are two incomplete sources of data that I use to verify the validity of my repeating rate estimates.

\footnotetext{
${ }^{4}$ Early and late entry into elementary school cause similar measurement error to repeated grades. If early and late entry are correlated with the primary variable of interest, this measurement error is also endogenous. My analysis avoids this issue by directly observing the year each individual completes their schooling, but other analysis should follow the recommendations I suggest in Section 6.3.
} 
First is a list of repeating rates reported in Heubert and Hauser (1998). These repeating rates are reported for 27 states in various years from 1979 to 1997 - there are only 81 observations in this dataset, meaning each state reports repeating rates an average of 3 times. I combine this with data from the Massachusetts Department of Elementary and Secondary Education from 1998-2012 to form a dataset of 97 observations of state-reported 9th grade repeating rates with which I can compare my estimates. I additionally compare my estimated repeating rates with the Current Population Survey's (CPS) October Education Supplement.

\subsection{Returns to Education and Experience}

I use the National Longitudinal Survey of Youth 1997 (NLSY97) and the Children of the National Longitudinal Survey of Youth 1979 (CNLSY), as these are two of the only microdata sets in which I can observe grade repeating. The NLSY97 surveyed 8,984 12 to 18 year olds in 1997 and reinterviewed them every year from 1997 to 2011, after which the survey became biennial. Importantly, the initial survey included an educational history, which included grade enrollment by year. I use this history, along with grade enrollment by survey year, to construct measures of repeating for the 9th grade and for any grade. I also observe a full employment history including wages, employment status, hours worked, and weeks worked. Following Bound and Freeman (1992), I omit individuals who do not have an ASVAB test score. The CNLSY is a continuation of the NLSY79, which surveyed the children of women in the originial NLSY79 sample. This sample includes 11,521 individuals born between 1970 and today, and includes the educational history and labor market outcomes of these individuals. I restrict my sample to only include individuals who had completed their education by the most recent survey in 2014, the youngest individuals in my sample were born in 1997. These public-use data are then merged with NLSY restricted geocodes, provided by the Bureau of Labor Statistics, for determination of the compulsory schooling laws each individual faced. Summary statistics for all data are provided in Table 1. 
Panel A of Table 1 shows summary statistics for enrollment changes. My preferred estimates of the annual 9th grade retention rate, the 8th to 9th grade enrollment change and the 9 th to 10 th grade enrollment change, are on average $6 \%$ across states and years, 1965-2013. In less than 5\% of the sample, the 8th to 9th grade enrollment change is negative and the 9 th to 10 th grade enrollment change is positive - these are omitted from my analysis. Panel B describes the CNLSY used in analysis of compulsory schooling laws. The CNLSY oversamples black individuals; they account for $34 \%$ of the observations. The average level of compulsory attendance is about 11 years, and the average educational attainment is 12.3 years. The CNLSY only identifies which individuals ever repeated the 9th grade; as a result, I am unable to identify individuals who repeated more than once. Panel $\mathrm{C}$ describes the NLSY97 sample used in analysis of black-white gaps and the returns to the GED. Here, I can observe all grade repeating, as well as individuals who repeated multiple grades. About $4 \%$ of the sample repeated the 9 th grade at least once, and $24 \%$ of the sample repeated any grade. ${ }^{5}$ Finally, Panel D describes the frequency of different minimum dropout ages from 1965 to 2014. Dropout ages below 16 are extremely rare, only occurring in two states (MS from 1979-93, AR from 1977-80). The most common minimum dropout age is 16, with 18 becoming more popular; 24 states had a minimum dropout age of 18 in 2014, compared with only 4 in 1965.

\section{9th Grade Repeating Rates}

\subsection{Estimation}

Administrative and nationally representative survey data on grade repeating rates are generally quite rare. At the national level, Haney et al. (2004) use enrollment data from the National Center for Education Statistics (NCES) to examine attrition between grades,

\footnotetext{
${ }^{5}$ The mean of 9 th grade repeats is about $5 \%$, because $0.7 \%$ of the sample repeated the 9 th grade multiple times. $6.6 \%$ of the sample repeated multiple grades.
} 
that is, students who do not proceed normally to the next grade due to retention or dropping out, from the 1960s to 2000s. They show that the average attrition rate between the 9th and 10th grades grew from about $3 \%$ in the late 1960 s to $12 \%$ in 2000 . The attrition rate between the 9 th and 10 th grades can be approximated as 9 th grade retention rate + 9th grade dropout rate -10 th grade retention rate. ${ }^{6}$ They do not directly compare the attrition rate to 9 th grade retention rates, but suggest a rise in 9 th grade retention as the predominant cause of this attrition change. In contrast, Hauser et al. (2007) use the Current Population Survey (CPS) to assemble annual repeating rate estimates for the United States - they claim that annual 9th grade retention rates were only between $2.2 \%$ and $4.2 \%$ from 1995 to 2005. State-level retention rates are rarely available, with administrative data coming from a study by the National Research Council (NRC) in 1999, as well as from the Massachusetts Department of Education (MADoE). In this section, I fill this gap in the literature by assembling a state-level panel dataset of 9 th grade repeating rate estimates, and testing their accuracy against the highly incomplete, but otherwise accurate administrative data to determine the proper dataset for use in this study and in future work on 9 th grade repeating. ${ }^{7}$

I assemble state-level repeating estimates from the two sources used in Haney et al. (2004) and Hauser et al. (2007): the NCES enrollment data and the CPS October Education supplement. The NCES data come from two programs - enrollment by grade (1st-12th) and state from 1965-2003 is from the NCES Annual Reports Program Historical Tables, and enrollment by grade and state from 2004-2014 is from the NCES Common Core of Data. These enrollment counts only cover public schools, which make up over $90 \%$ of all students in the United States. Although these enrollment data do not directly measure 9th grade retention

\footnotetext{
${ }^{6}$ The 9 th to 10 th grade attrition rate can also be affected by movement between private and public schools, death rates, and immigration, but these are have much smaller effects than retention and dropouts.

${ }^{7}$ Smaller-scale studies of 9th grade retention have used nationally representative survey data in a limited number of years (Planty et al., 2009) or analysis of school district-level data on repeating (Allensworth and Easton 2005 and many others). These estimates are generally in the 5-15\% range, are likely more accurate than my cohort-level enrollment-based estimates, but are available for far fewer years or are not suited for analysis of national trends.
} 
rates, the growth in enrollment between 8th and 9th grades and the attrition between 9th and 10th grades may be reasonable estimates of retention.

Due to the repeated survey structure of the CPS, it provides a direct measure of 9th grade repeating rates. I first restrict my sample to only include individuals enrolled in the 9th grade in the first year they were surveyed. I then observed their grade in the second year they are surveyed; 9th grade repeaters are enrolled in the 9 th grade in both years. ${ }^{8} \mathrm{I}$ then average these 9 th grade repeating rates within each state-year pair to assemble a panel dataset of 9th grade repeating rates from 1976-2016.

For the NCES and CPS estimates to be valid estimates of the true 9th grade repeating rate, they should be highly correlated with and similar in magnitude to the true rate. To begin, I examine the correlations between the NCES and CPS estimates of the 9th grade repeating rates and the true 9 th grade repeating rates from the $\mathrm{NRC}$ and Massachusetts DoE. Correlations and p-values from the test $H_{0}: \rho=0$ are shown in Table $2 .{ }^{9}$

Table 2 clearly shows a weak correlation between the CPS estimate and the true repeating rates from the NRC and MA, while showing strong correlations for the enrollment change estimates from the NCES, particularly for the 9th-10th grade enrollment change. While none of these estimates show perfect correlation with the 9th grade repeating rate, the NCES estimates are potentially valid, but noisy, measures of the true 9th grade repeating rate. However, these correlation tests do not verify that these estimates are comparable in magnitude to the true 9th grade repeating rate, only that annual and between-state varia-

\footnotetext{
${ }^{8}$ Some 9th graders observed for the first time may already be repeaters. However, if the CPS is a valid dataset for 9 th grade repeating analysis, the proportion of individuals who were already 9 th grade repeaters in the first year surveyed would represent the proportion of the 9th grade population who are repeaters for a given state-year pair. Those who repeat the 9 th grade for a 2 nd time should be representative of the population that repeats the 9 th grade more than once.

${ }^{9}$ All correlations and regressions impose that the 8 th to 9 th grade enrollment change is non-negative and the 9 th to 10 th grade change is non-positive. For the $<5 \%$ of observations violating these assumptions, the enrollment change is set to 0 .
} 
tion is proportionate. To test similarity in magnitude, I perform a series of OLS regressions without constants. A valid estimate of the 9 th grade repeating rate will have a high $R^{2}$ and a coefficient estimate near $1 .^{10}$

Table 3 shows results from regressions of the true 9th grade repeating rates from the NRC and MA on my 9th grade repeating rate estimates. Columns (1) and (2) show similar results - the NCES estimate is $12-14 \%$ larger than the true 9th grade repeating rate on average, but shows a high $R^{2}$, the 9 th grade to 10 th grade change explains nearly $75 \%$ of the variation in the true 9 th grade repeating rate. Column (3) shows the CPS estimate is $24 \%$ smaller than the true 9th grade repeating rate on average, and explains substantially less variation in the true repeating rate than the enrollment change estimates. Column (4) presents an alternative way to rank these estimates - the 9th-10th grade enrollment change explains the majority of the variation in the true repeating rates, the 8th-9th grade change explains a smaller portion of the variation, and the CPS estimate has no explanatory power in comparison to the other two estimates. ${ }^{11}$ Given that the $R^{2}$ in column (4) is only slightly larger than in column (1), the 9th-10th grade enrollment change appears to be a strong estimate of the true 9 th grade repeating rate, while the 8th-9th grade enrollment change is a still a meaningful, but noisier estimate.

\subsection{Stylized Facts}

From Table 1, the average 9th grade repeating rate in a US state from 1965-2014 was about $8 \%$ per year. However, the 9 th grade repeating rate has not been stable over time. Figure 1 shows enrollment by grade for the 1977 and 2014 graduation cohorts, for all public

\footnotetext{
${ }^{10}$ The $R^{2}$ from a regression without a constant is not directly comparable to the $R^{2}$ from regressions with a constant, as imposing the point $(0,0)$ in the regression modifies the interpretation of residuals. Nevertheless, in comparing three models without constants, $R^{2}$ provides a meaningful basis on which I can rank the validity of my estimates.

${ }^{11}$ The 8th-9th grade enrollment change and 9th-10th grade enrollment change are highly collinear $(\rho=$ $0.66)$, so the relative magnitudes of these two point estimates may be inaccurate.
} 
school students in the United States. ${ }^{12}$ The 1977 cohort in Graph (a), who entered the 1st grade in 1965 and were in the 9 th grade in the 1973-74 academic year, is representative of historical enrollment patterns in the United States. The 1st grade is substantially larger than the 2 nd grade, as many students are retained in early elementary education for non-academic reasons, i.e. to aid in their social and behavioral development. Enrollment is relatively stable from the 2nd grade until high school, with minor fluctuations between grades and a small increase in 9th grade enrollment relative to 8th grade enrollment. Then, enrollment drops from the 9 th to 12 th grades, as students are legally allowed to drop out of school - usually, around age 16 in the mid-1970s.

The 2014 cohort in Graph (b) shows a markedly different pattern. 1st grade enrollment is no longer substantially larger than 2nd grade - this is likely due to the growing popularity of Kindergarten; socially and behaviorally underdeveloped children now are likely to repeat Kindergarten, not the 1st grade. As in the 1970s, enrollment is stable in elementary and middle school. However, the 9 th grade is substantially larger than the 8th grade, or any other grade for the 2014 cohort; There are over 350,000 more 9th graders in the 2010-11 academic year than 8th graders in the 2009-10 academic year (9.7\% larger), and over 250,000 more 9th graders in 2010-11 than 10th graders in 2011-12 (6.8\% larger). The decline in high school is not as steep for the 2014 cohort as for the 1977 cohort, due to higher compulsory schooling requirements and increased graduation rates over the past 50 years.

Figure 2 shows the 9th grade repeating rate estimates calculated in Section 4.1 from 1965-2014. The top line shows the 8th-9th grade enrollment change estimate, and the bottom line shows the 9th-10th grade enrollment change estimate. These two estimates are not exactly equal in magnitude, the 8th-9th grade change is generally 1 to 2 percentage points larger than the 9 th to 10 th grade change, but the pattern is highly symmetric. Taking the

\footnotetext{
${ }^{12}$ According to Kena et al. (2016), 90.3\% of all US Elementary and Secondary students are enrolled in public schools.
} 
9th-10th grade change as the preferred estimate of the 9th grade repeating rate, from 1965 to the early 1980 s the 9 th grade repeating rate was $2-5 \%$ per year. In the 1980 s, the rate grew dramatically, reaching a peak of $11.4 \%$ in 1998 , then rapidly declined after 2003 . The center line shows the enrollment change from 8th to 10th grade; this shows no discernible trend and is generally near 0 , verifying that the estimated growth in 9 th grade repeating is not caused by immigration, moving from private to public school, or changes in dropouts in the 9 th or 10 th grades. If the estimated growth in 9th grade repeating were caused by immigration or moving from private to public school, we would see an increase in the 8th to 10 th grade enrollment change. If it were driven by an increase in the 9 th grade dropout rate or a decrease in the 10 th grade dropout rate, we would see a decrease in the 8th to 10th grade enrollment change. Overall, these estimates show that 9th grade repeating more than tripled from the 1960s to the late 1990s; the growth in 9 th grade repeating is one of the greatest educational trends of the past 50 years, and yet it has been largely ignored by the economics literature.

\section{Compulsory Schooling}

\subsection{Compulsory Schooling Law Effects on 9th Grade Repeating}

The literature on the causes of the rise in 9th grade repeating is remarkably sparse; the

only study to posit potential causes, Haney et al. (2004) proposes three reasons why 9th grade retention rose from the 1970s to the 2000s. First, states in the 1970s began tying promotion to "minimum competency testing;" this tested students on basic reading and arithmetic skills, and caused increases in both the dropout rate and 9 th grade retention rate (Kreitzer et al., 1989; Shepard and Smith, 1989). Second, academic requirements for promotion and graduation were strengthened in the 1980s. Third, high-stakes testing tied 
promotion to performance on annual standardized tests. ${ }^{13}$

I argue that these institutional changes may have been the driving force behind the growth in 9th grade retention, but that none of these changes would have caused such a dramatic increase in retention without an external force preventing students from dropping out of school. A 9th grader who is told he or she will be retained in the 9th grade for an additional year would have a strong incentive to drop out of school, as they would be forced to forgo an extra year in the labor market to achieve the same educational attainment as their non-retained peers. Compulsory schooling laws make it illegal for these students to leave school in the 9th grade - from 1965 to today, only two states (Arkansas and Mississippi) ever had a minimum dropout age below 16, and after 1994 no state had a minimum dropout age below 16 .

A first-time 9 th grader will typically enter the 9 th grade at age 14 , so a minimum dropout age of 16 creates a binding enforcement mechanism that causes a retained 9 th grader to actually repeat the 9 th grade instead of dropping out of school. Although no on-track 9th grader was legally allowed to drop out of school, in the 2004-2005 school year 9th grade dropouts made up over $23 \%$ of all dropouts in the country (Sable et al., 2007). The existing literature has ignored the role of compulsory schooling laws (CSLs) on 9th grade retention; this is especially surprising, since there were many compulsory schooling law increases across the country from the mid-1980s to mid-2000s, when the majority of the rise in 9th grade retention occurred. Figure 3 shows the average minimum dropout age faced by an American high school student from 1965 to 2014, calculated as the average dropout age across states, weighted by state enrollment in grades 9-12.

\footnotetext{
${ }^{13}$ This is considered a separate change from minimum competency testing as high-stakes testing tests students on skills appropriate for their grade level, while minimum competency testing tests far below grade level.
} 
Figure 3 shows that the typical high schooler faced a minimum dropout age of 16.3-16.5 from 1965 to the mid-1980s. Over the next 20 years, the dropout age grew by about 1 year, peaking at 17.2 in 2005, then falling slightly to an average minimum dropout age of 17.1 today. Overall, states changed their minimum dropout age a total of 61 times in this time period. The minimum dropout age is likely to continue to rise, as in President Barack Obama's 2012 State of the Union Address, he "call[ed] on every state to require that all students stay in high school until they graduate or turn eighteen."

I estimate the causal effect of changes in compulsory schooling laws on the 9th grade retention rate using difference-in-differences estimation with the estimating equation below:

$$
\% \text { Change }_{s, t}=\beta_{0}+\beta_{1} \text { Min Drop Age } e_{s, t}+\gamma_{t}+\lambda_{s}+\varepsilon_{s, t}
$$

In equation 6 , the $\%$ Change $_{s, t}$ refers to the 9 th grade repeating rate estimate in state $s$ and year $t$, Min Drop $A g e_{s, t}$ refers to the minimum dropout age in a state-year pair, and $\lambda_{s}$ and $\gamma_{t}$ are state and year fixed effects, respectively. $\beta_{1}$ is the coefficient of interest, the causal effect of an increase in the minimum dropout age on 9 th grade retention. ${ }^{14}$ This specification has the advantage of being immune to between-cohort population changes. For example, the large population growth in the West and South over the past 50 years does not affect the level of the outcome variable. Given the regression specification, the standard identifying assumption for difference-in-differences estimation applies: states not changing their minimum dropout age have parallel trends in 9th grade retention to states changing their minimum dropout age prior to the law change.

Table 4 shows the results from estimating equation 6. Columns (1) and (5) of Table 4 show that states with higher minimum dropout ages have greater 9 th grade retention. In the

\footnotetext{
${ }^{14}$ This equation does not estimate the overall effect of compulsory schooling on 9th grade retention, as there are no states without compulsory education. As a result, I am unable to test whether without compulsory schooling laws, 9th grade retention would not exist.
} 
difference-in-differences specifications in columns (4) and (8), one extra year of compulsory education increases the 9 th grade retention rate by approximately 0.7 percentage points an $11.5 \%$ increase relative to the mean 9 th grade retention rate of $6.1 \%{ }^{15}$ This suggests that while the expansion of compulsory schooling laws is not entirely responsible for the rise in 9th grade retention, compulsory schooling law changes still played an important role. Continuing to raise the minimum dropout age may additionally erase the recent reductions in 9 th grade retention rates (from $11.4 \%$ in 1998 to $5.3 \%$ in 2012).

To test the identifying assumptions of the difference-in-differences model, I perform the conventional event study-style test of lags and leads of compulsory schooling law changes. I estimate the following model:

$$
\% \text { Change }_{s, t}=\alpha+\sum_{k=-5}^{5} \beta_{k} \mathbf{1}\left(C S L \text { Increase }_{t+k}\right)+\gamma_{t}+\lambda_{s}+\varepsilon_{s, t}
$$

In equation 7 , the term $\mathbf{1}\left(C S L\right.$ Change $\left._{t+k}\right)$ is an indicator for an increase in the minimum dropout age in year $t+k$ - states that change their minimum dropout age multiple times within 5 years are omitted, as it is not possible to assign treatment status in this event study structure for these states. This leaves 33 minimum dropout ages changes used to verify the parallel trends assumption. The endpoints $\mathbf{1}\left(C S L\right.$ Increase $\left._{t-5}\right), \mathbf{1}\left(C S L\right.$ Increase $\left._{t+5}\right)$ are cumulative, meaning that all observations 5 or more years away from a CSL change are assigned the same treatment status. Finally, $\beta_{t-3}$ is normalized to 0. Figure 4 shows the coefficient estimates $\left\{\beta_{-5}, \ldots, \beta_{5}\right\}$ from the regression in equation 7 .

Figure 4 shows no discernible pre-existing trends in the 9th grade retention rate, aside from possibly a small deviation at $(t-5)$. Looking at the preferred 9 th grade retention

\footnotetext{
${ }^{15}$ Standard errors are estimated as heteroskedasticity-robust, as this (or clustering at the state-year pair, which is equivalent) is conventional in the CSL literature (Angrist and Krueger, 1991; Acemoglu and Angrist, 2000). Nevertheless, clustering may be appropriate - Table A1 in the Appendix compares standard errors from robust standard errors, overlapped multiway clustered standard errors as in Cameron et al. (2011), and standard errors clustered at the state level.
} 
rate in Graph (b), Figure 4b shows a small, but noticeable increase in 9th grade retention, corresponding to a reduction in the 9th-10th grade enrollment change, immediately upon changing the minimum dropout age. This effect may only be temporary, as the coefficient estimate reverts to its pre-law change level within 3-4 years, but if so, this temporary reduction is strong enough to cause a 0.7 percentage point increase in the 9 th grade retention rate on average. ${ }^{16}$

Next, I perform the same analysis to test for CSL effects on the change from 7th to 8th grade, from 10 th to 11 th grade, and from 11 th to 12 th grade. Table 5 shows results from estimation of equation 6 on these three outcomes. The change from 7 th to 8 th grade is a placebo test, as CSLs should not have any effect on promotion from 7th to 8th grade. I would see positive effects on the changes from 10th to 11th and from 11th to 12th grades if CSLs prevent on-track high schoolers - that is, those who are promoted to the next grade from dropping out of school.

All 3 of the outcomes in Table 5 are unaffected by CSL changes. This is unsurprising for the 7 th to 8 th grade enrollment change, but is somewhat unexpected for the other two outcomes. CSLs are generally thought of as dropout prevention tools, and their use as instruments in IV regressions of the returns to education hinges on the idea that CSLs, by preventing teenagers from dropping out of school, increase educational attainment. Given these findings, it is crucial to reexamine the validity of CSLs as instruments in the modern era using data that allows observation of both educational attainment and grade repeating.

\subsection{Correcting IV Estimates of the Returns to Education}

Most publicly available microdata do not allow the researcher to observe repeated grades in any form. However, some longitudinal surveys track each individual's grade enrollment

\footnotetext{
${ }^{16}$ This temporary reduction may also be caused by states with multiple CSL changes in a short timespan being dropped from the sample.
} 
in each year, allowing the observation of repeated grades. Other surveys ask a detailed history of grade repeating. For this analysis, I use the National Longitudinal Survey of Youth 1979 Children and Young Adults (CNLSY), which provides a wide time horizon, covering individuals born between 1970 and 1999. In this period I observe a large number of CSL changes - 28 states change their CSL in this time period. The CNLSY surveys individuals biennially, but in each survey asks a history of grade repeating. Each individual who ever reports having repeated the 9 th grade is coded as a 9 th grade repeater. ${ }^{17}$

Angrist and Krueger (1991) use quarter of birth as an instrument in their well-known estimation of the effects of education on wages. Acemoglu and Angrist (2000) modify this instrument, using quarter of birth interacted with year of birth, and supplement this by directly including compulsory education as an instrument. ${ }^{18}$ I replicate their methodology in the CNLSY, estimating the private returns to education, beginning with the following OLS estimating equation:

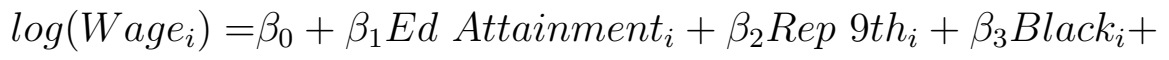

$$
\begin{aligned}
& \beta_{4} \text { Hispanic }_{i}+\beta_{5} \text { Female }_{i}+\lambda_{i t}+\gamma_{i s}+\varepsilon_{i}
\end{aligned}
$$

In equation 8, I modified Acemoglu and Angrist's OLS estimation in two ways: first, I included black, hispanic, and female individuals in the sample. This analyzes a different population, thus resulting in a different local average treatment effect than that found by Acemoglu and Angrist, but inclusion of these groups will estimate a LATE that is closer to the population-level average treatment effect. Second, I control for whether an individual repeated the 9 th grade. In OLS estimation, this is unlikely to change the estimate of $\beta_{1}$ by

\footnotetext{
${ }^{17} \mathrm{~A}$ small number of individuals may have repeated the 9th grade more than once; however, the question asked in the CNLSY does not permit the observation of these multi-time repeaters.

${ }^{18}$ Acemoglu and Angrist (2000) note that related literature (e.g. Imbens and Angrist 1994) shows 3 quarter of birth instruments cause the 2SLS estimate to be strongly biased toward the OLS estimate due to its 1st stage weakness, while the quarter of birth interacted with year of birth produces estimates largely unaffected by weak instrument bias.
} 
a significant amount. Selection bias caused by correlation between educational attainment and grade repeating may exist, but the effect of grade repeating on wages is likely to be quite small. I also control for state of residence $\gamma_{i s}$ and birth year $\lambda_{i t}$, as in Acemoglu and Angrist (2000).

OLS regressions provide a comparison for the 2SLS estimation of the effects of educational attainment on wages. As 9th grade repeating is likely endogenous in equation 8, as is educational attainment, I use compulsory schooling and/or quarter of birth as instruments for both of these endogenous variables. Compulsory education instruments are three indicators for each level of compulsory education, defined as $C E_{i s}=$ Minimum Dropout $_{\text {Age }}-$ School Entry Age for state $s$, with a minimum of $C E=9$ and a maximum of $C E=12$. Quarter of birth is as in Acemoglu and Angrist (2000), with an indicator for quarter of birth interacted with a year of birth fixed effect. The three 2SLS regression equations are given below:

$$
\begin{gathered}
\text { Ed Attainment } i=\alpha_{0}+\alpha_{1} C E_{i s}+\alpha_{2} Q O B_{i} \times \lambda_{i t}+\eta X_{i}+u_{i} \\
\operatorname{Rep} 9 t_{i}=\delta_{0}+\delta_{1} C E_{i s}+\delta_{2} Q O B_{i} \times \lambda_{i t}+\psi X_{i}+v_{i} \\
\log \left(\text { Wage }_{i}\right)=\beta_{0}+\beta_{1} \text { Ed } \widehat{\text { Attainment }_{i}+\beta_{2} \widehat{\operatorname{Rep}} \text { th }_{i}+\Gamma X_{i}+\varepsilon_{i}}
\end{gathered}
$$

The controls in $X_{i}$ are identical to those in equation 8, except regressions with quarter of birth instruments do not contain separate year of birth fixed effects due to collinearity. I estimate the selection bias caused by CSL instruments by comparing $\hat{\beta}^{I V}$ when correctly accounting for 9 th grade repeating to $\hat{\beta}^{I V}$ when not accounting for 9 th grade repeating. Table 6 presents results from these regressions.

Columns (1) and (2) of Table 6 show comparisons of OLS to IV regressions ignoring 9th 
grade repeating. Panel A shows results for compulsory schooling law instruments - binary indicators of the number of compulsory years of education in each state-year pair. Column (2) shows a much larger effect of education on wages than the OLS estimate, typical for compulsory schooling instruments as the local average treatment effect (LATE) is larger than the average treatment effect, even with selection bias in the OLS case (see Imbens and Angrist 1994 for details). Columns (3) and (4) show comparisons of OLS to IV regressions accounting for 9 th grade repeating. Unfortunately, the 1st stage shows that these compulsory schooling instruments are weak, with an F-statistic of only 3.4 when not accounting for 9th grade repeating and 1.584 when accounting for 9 th grade repeating. A comparison of column (2), omitting 9th grade repeating, to column (4), including 9th grade repeating, shows that the omission of 9 th grade repeating from the model specification causes approximately $8 \%$ bias in the returns to education. ${ }^{19}$

Panels B and $\mathrm{C}$ of Table 6 show results using quarter of birth instruments. I show that quarter of birth instruments are strong as predictors of educational attainment, as asserted by Imbens and Angrist (1994) and Acemoglu and Angrist (2000). This results in a slightly smaller estimate than in Panel A, as weak instruments positively bias the IV estimate of the returns to education. Including 9 th grade repeating in the estimation, however, results in a markedly lower estimate of the wage return to education. Although the instruments in column (4) are weak, with an F-statistic of only 2.7, this should bias the return to education upward, in the direction of OLS selection bias (Bound et al., 1995). Omission of 9th grade repeating thus causes at least $38 \%$ bias in the estimate of the private wage return to education when using quarter of birth instruments.

Inclusion of compulsory schooling law and quarter of birth instruments in Panel $\mathrm{C}$ reveals a similar pattern - omission of 9th grade repeating in this specification causes $23 \%$ upward

\footnotetext{
${ }^{19}$ Point estimates in both column (2) and column (4) should both be upward biased due to instrument weakness. However, I cannot determine which estimate faces larger bias.
} 
bias in estimation of the returns to education. Although the returns to repeating the 9 th grade are unbelievably high - it is unreasonable to think that repeating the 9 th grade causes wages to increase by $80-100 \%$ - this is the result of instrument weakness in predicting 9 th grade repeating, and suggests that, if anything, the estimate of the return to education is still too large after accounting for 9th grade repeating. Weak instrument bias is in the direction of OLS selection bias. OLS estimates of the returns to education face positive selection bias from endogenous variables such as ability and household income, so IV estimates using weak instruments will be positively biased. Overall, unless accounting for 9th grade repeating, compulsory schooling instruments are invalid and create severe bias.

\section{Repeated Grades and Experience}

\subsection{Black-White Wage and Hours Gaps}

In this section, I consider how poor measurement of potential labor market experience biases estimates of the black-white wage and employment gaps. To understand the channel by which measurement error in experience biases these estimates, consider the regression model estimated by Bound and Freeman (1992):

$$
\log \left(\text { Wage }_{i}\right)=\beta_{0}+\beta_{1} \text { Black }_{i}+\alpha E d \text { Attainment }_{i}+\gamma \text { Experience }_{i}+\eta \operatorname{Urban}_{i}+\varepsilon_{i}
$$

The terms Ed Attainment And $_{i}$ Experience ${ }_{i}$ are indicators for each level of educational attainment and potential labor market experience, respectively. Potential labor market experience is calculated as $\min ($ Age $-E d$ Attainment - 6, Age - 18) to explicitly account for selection into college attendance. However, repeated grades are not accounted for in this measure of experience. The key consideration here is not that estimating equation 11 will result in a biased estimate of $\gamma$, but rather that the primary coeffiecient of interest, $\beta_{1}$, may 
be biased.

I use the NLSY97 to reexamine the early career black-white wage gap, accounting for repeated grades. In the NLSY97, blacks are almost twice as likely as whites to have their potential labor market experience misstated due to grade repeating; in 2010, 16\% of whites and $31 \%$ of blacks had repeated at least one grade, causing Age-Ed Attainment -6 to overstate their experience. Since experience has a positive effect on wages, systematically overstating the level of experience for black workers more than for white workers will result in a residual black-white wage gap that is too large. Some of the residual black-white wage gap estimated by Bound and Freeman can likely be attributed to differences in repeating rates by race, not to labor market discrimination. I replicate their regression model, but remeasure experience as min(Age-Ed Attainment - Repeated Grades - 6, Age-Repeated Grades - 18) to accurately measure potential labor market experience: that is, the number of years since each individual completed their schooling. Table 7 reports results from estimating equation 11 and an analogous returns to employment regression for early career (2000-2005, ages 18-25) and slightly later career (2006-2011, ages 22-31) workers.

In Panel A, column (1) finds a $21 \%$ gap between black and white wages, close to the $18 \%$ estimate that Bound and Freeman find for workers in the 1980s. However, when controlling for repeated grades in column (2), the gap closes by 2.4 percentage points; failing to account for repeated grades overstates the residual black-white wage gap by $13 \%$ for early career workers. Columns (3) and (4) show a similar pattern, with smaller bias in column (3). This is due to 2 reasons: first, most college-educated workers in the sample begin entering the labor force from 2006-2011, and college-educated workers of any race are unlikely to have repeated grades. There is still a racial gap for college graduates, however; $14 \%$ of black college graduates in the NLSY97 repeated a grade, while only $5 \%$ of white college graduates repeated a grade. The second, and likely more important reason for the smaller bias 
in column (3) is because mismeasurement in experience is less important for older workers. In column (1), most individuals who repeated grades have their experience overstated by 25-100\%. In column (3), since these workers now have 5-10 years of experience, experience is overstated by only 10-20\%. The bias caused by misstating experience is less important for older workers, as it constitutes a smaller portion of their overall experience level.

Panel B shows no bias in the black-white employment gap caused by mismeasurement of experience. This is because experience appears to have little effect on employment status. The full set of experience indicators for the black-white wage gap and black-white employment gap are shown in Tables A2 and A3 - only two of the experience level indicators in columns (1) or (3) are significantly different from the baseline level of 0 in Table A3. While experience has large wage returns (8-10\% per year), it has small employment returns $(0.5 \%$ per year), causing little to no bias in the black-white employment gap regressions. Repeated grades are an important consideration in future estimation of black-white wage differentials. The substantial correlation between grade repeating and race cause grade repeating to be key in ensuring an unbiased estimate of the residual black-white wage gap.

\subsection{Returns to GED}

Grade repeating, as one might expect, is highly correlated with education. Table 8 shows the proportion of individuals in the NLSY97 with each level of education who repeated at least one grade in elementary and secondary school.

Cameron and Heckman (1993) estimate the returns to a GED in the NLSY79, finding that the GED is not equivalent to a regular high school diploma, and that in fact GED recipients are remarkably similar to high school dropouts who do not receive a GED. Table 8 confirms that this is true, showing that the grade repeating rate for GED recipients is almost identical to that for high school dropouts. Overall, GED recipients' repeating rates 
are 3.5 times as large as the repeating rates for high school graduates. The incredibly high grade repeating rates of non-high school graduates cause substantial measurement error of potential labor market experience when estimating wage and annual hours worked returns, whether comparing high school graduates to GED recipients or to high school dropouts. I estimate the bias caused by this measurement error in the NLSY97 by replicating the OLS estimation of Cameron and Heckman (1993) as below:

$$
\begin{aligned}
\log \left(\text { Wage }_{i}\right)= & \beta_{0}+\beta_{1} \text { GED }_{i}+\beta_{2} \text { Dropout }_{i}+\beta_{3} \text { HS Diploma } \\
i & +\beta_{4} \text { Associates }_{i} \\
& +\beta_{5} \text { Experience }_{i}+\beta_{6} \text { Urban }_{i}+\beta_{7} \text { Black }_{i}+\beta_{8} \text { Hispanic }_{i}+\beta_{9} A S V A B_{i}+\varepsilon_{i}
\end{aligned}
$$

In equation 12 , the primary variables of interest are the coefficients on educational attainment, $\beta_{1}, \beta_{2}, \beta_{3}$, and $\beta_{4}$. I have set the baseline level of educational attainment as a bachelor's degree; this is unconventional, but is done to make coefficient estimates comparable across specifications, regardless of whether I account for grade repeating or not. Since the overall grade repeating rate is quite low for bachelor's degree recipients $(6.1 \%)$, the baseline return to education will be largely unaffected by accounting for grade repeating. If I had instead followed Cameron and Heckman (1993) and set high school dropouts as the baseline, the coefficient estimates on high school diplomas and bachelor's degrees would appear biased, not the coefficient estimate on the GED. Here I follow the conventional potential labor market experience measure, Experience $=$ Age - Ed Attainment -6 , and correct for grade repeating by letting Experience $=$ Age - Ed Attainment - Grade Reps $-6 .{ }^{20}$ This regression only includes men, and has controls for urban status, race, and standardized ASVAB score. Table 9 presents results from this estimation, with wages and hours worked as outcomes.

\footnotetext{
${ }^{20}$ Cameron and Heckman (1993) use lifetime weeks worked as their primary experience measure. As mentioned previously, this measure is not subject to measurement error from repeated grades, but is endogenous with factors influencing labor force participation, and is rarely used today.
} 
Panel A of Table 9 shows the effects of educational attainment on hourly wages. Column (1) presents estimates with the conventional experience measure; high school graduates earn $14 \%$ less than college graduates, while GED recipients earn $37 \%$ less than college graduates a GED recipient earns $27 \%$ less than a high school diploma recipient, similar to the earnings of a high school dropout. Column (2) shows the difference when only accounting for 9th grade repeating - the wage penalty from a GED is reduced by 1 percentage point, but a Chow test shows this difference is not significant. Column (3) shows the returns to a GED when properly accounting for all repeated grades. The GED is still far less valuable than a college degree and high school diploma, but the gap is smaller than in column (1). GED recipients earn $32.7 \%$ less than college graduates, while high school graduates still earn $14 \%$ less than college graduates; this makes the wage gap between GED recipients and high school graduates only $22.2 \%$, not $27 \%$ as suggested in column (1). A similar bias is present for high school dropouts; estimates of the wage return to a GED are biased by $10.4 \%$ and estimates of the wage return to dropping out of high school are biased by $10.9 \%$ when failing to account for repeated grades. As a result, studies where the baseline educational attainment is chosen as less than a high school diploma overstate the wage returns to completing high school.

Panel B shows the effects of educational attainment on annual hours worked. Cameron and Heckman test annual hours worked to demonstrate that GED recipients are similar to high school dropouts in their labor supply decisions on the intensive margin (hours worked while employed). ${ }^{21}$ College graduates and high school graduates work similar hours; high school graduates work only 2-3\% fewer hours than college graduates in all 3 specifications. However, GED recipients work far fewer hours than college and high school graduates. Column (1) shows a $16.2 \%$ labor supply gap between GED recipients and college graduates and

\footnotetext{
${ }^{21}$ This measure of annual hours worked also partially includes labor supply on the extensive margin. It includes the decision to work a part-time or full-time job, as well as changes in employment status. Observations of 0 hours worked in a year are dropped.
} 
a $20.4 \%$ gap between high school dropouts and college graduates. This translates to a $14 \%$ gap between GED recipients and high school graduates and a 18.3\% gap between high school dropouts and high school graduates. However, accounting for repeated grades changes these gaps substantially; accounting for 9th grade repeating reduces the labor supply gap for GED recipients by $21 \%$, and accounting for any repeated grade reduces the hours gap by an additional 10.7\%. Overall, failure to account for repeated grades causes no bias in labor supply estimation for high school graduates, but causes $33.9 \%$ bias in labor supply estimation for GED recipients and $22.9 \%$ bias for high school dropouts. These findings suggest that while the bias caused by grade repeating in OLS estimation of the returns to education may be smaller than in IV estimation, it is still crucial to account for repeated grades in any estimate of the returns to education.

\subsection{Age as an Alternative Experience Measure}

My results on the black-white wage gap and the returns to the GED demonstrate that the conventional measure of potential labor market experience may bias estimates in the presence of grade repeating. However, the ideal solution of directly accounting for repeated grades in the construction of potential labor market experience is impossible in many datasets. The Census, ACS, CPS, and other data sources do not measure grade repeating, so an alternative measure of labor market experience is needed that is not affected by grade repeating.

I propose that researchers should simply control for age. Age is highly related to the conventional measure of potential labor market experience (as it is perfectly collinear with potential experience and educational attainment), but does not suffer from endogenous measurement error. As a result, it can serve as a proxy variable for labor market experience without being affected by repeated grades.

I test whether the inclusion of age can improve our estimates when grade repeating is 
unknown by comparing my previous estimates to estimates controlling for age in lieu of a more conventional experience measure. Table 10 shows results from the black-white wage and employment gaps. Here, rather than using the experience measure in Bound and Freeman (1992), I use Age-Educational Attainment-6 and Age-Educational AttainmentRepeated Grades - 6. ${ }^{22}$ I compare these estimates to estimates when only controlling for age.

Columns (1) and (4) in Table 10 show the black-white wage and employment gaps using the conventional experience measure, and columns (3) and (6) show the gaps correcting for repeated grades. Columns (2) and (5) control for age instead of potential labor market experience. Controlling for age does not affect the estimate of the black-white wage or employment gaps, relative to the conventional experience measure. None of the experience measures cause statistically significant changes in the residual black-white wage gap estimate, although the 13 to $14 \%$ difference between the wage gap in column (3) compared to the gaps in columns (1) and (2) has economic significance. In estimation of the residual black-white wage and employment gaps, age is no worse as a control than potential labor market experience.

In Table 11, I test whether age reduces the bias in estimating the returns to the GED. Columns (1) and (3) of Table 11 are identical to columns (1) and (3) of Table 9, except for the pairwise test statistics. Column (2) shows results controlling for age instead of a conventional labor market experience measure. The wage return to the GED in Panel A is significantly greater when controlling for age than when controlling for the conventional labor market experience measure. Controlling for age results in a slightly greater estimate of the wage return to the GED than controlling for experience and repeated grades, but this different is not significant. Age improves the accuracy of the estimate of the wage return to the GED, compared to the conventional measure of potential experience. Panel B shows a

\footnotetext{
${ }^{22}$ The point estimates and repeated grades bias when using this experience measure are almost identical (18-20\% black-white wage gap, $13 \%$ bias) to the previous estimates in Table 7.
} 
similar pattern to Panel A; controlling for age in estimating the labor supply gap between GED recipients and high school graduates results in extremely low bias (6\%), while controlling for potential labor market experience results in substantially greater bias (34\%).

My findings suggest that researchers concerned about bias from repeated grades should, at minimum, test whether the use of age in lieu of labor market experience affects point estimates. When repeated grades cause small (e.g. black-white wage gaps) or no (e.g. blackwhite employment gaps) bias, the use of age as a control variable should not affect the estimate of interest. However, when repeated grades cause substantial bias (e.g. returns to GED), the use of age improves the accuracy of the estimate of interest, and should be the preferred proxy variable for labor market experience.

\section{Conclusion}

Repeated grades are an important, yet widely overlooked issue in the economics of education. The tripling of 9 th grade repeating rates from the 1970s to the late 1990s is of critical importance to any researcher attempting to measure educational attainment or labor market experience, but a lack of detailed data on grade repeating has caused much of the contemporary literature in labor economics to inadvertently introduce bias into their estimates. Compulsory schooling instruments in particular have become less valid for individuals born in the past 40 years. Efforts need to be made to circumvent their endogeneity with 9th grade repeating. IV estimation of the returns to schooling can cause bias of at least $38 \%$ when failing to account for the simultaneous effects of CSLs and/or quarter of birth on 9th grade retention.

Similarly, a modification of the common experience measure, Experience $=$ Age Educational Attainment - 6, is needed to avoid the accidental introduction of endoge- 
nous measurement error into related estimates. Failing to correctly measure potential labor market experience causes $13 \%$ bias in the black-white wage gap for young workers, 10-11\% bias in the wage return to a GED or dropping out of high school, and $23-34 \%$ bias in the labor supply gap for GED recipients and high school dropouts. All in all, these findings suggest that solving this measurement error problem is crucial for future work, as any research investigating people who finished their schooling in the 1980s, 1990s, or 2000s is subject to this repeated grades problem.

Applied researchers must be cognizant of this measurement error problem and modify their measure of experience to avoid bias. When using longitudinal data, such as the PSID or NLSY, the solution is simple - grade repeating can be explicitly accounted for in the measure of labor market experience and can be controlled for in the primary regression model. However, when using cross-sectional data, the solution is more complicated. Age is likely a better proxy for labor market experience than the conventional measure of Age Educational Attainment - 6, as it does not suffer from endogenous measurement error. Controlling for age eliminates the bias in the returns to the GED, while not worsening the bias in the black-white wage gap. I suggest that researchers using cross-sectional data should control for age instead of experience, or at minimum, as a robustness test, to avoid bias from repeated grades. 


\section{References}

Elementary/Secondary Information System. U.S. Department of Education. Institute of Education Sciences, National Center for Education Statistics.

Historical Tables 83 Reports: Elementary and Secondary Enrollment. U.S. Department of Education. Institute of Education Sciences, National Center for Education Statistics.

Statistical Reports: Grade Retention. Massachusetts Department of Elementary \& Secondary Education, Information Services.

Acemoglu, D. and Angrist, J. (2000). How Large are Human-Capital Externalities? Evidence from Compulsory Schooling Laws. NBER macroeconomics annual, 15:9-59.

Allensworth, E. M. and Easton, J. Q. (2005). The On-Track Indicator as a Predictor of High School Graduation. Consortium on Chicago School Research, University of Chicago Chicago, IL.

Angrist, J. D. and Krueger, A. B. (1991). Does Compulsory School Attendance Affect Schooling and Earnings? The Quarterly Journal of Economics, 106(4):979-1014.

Aragon, S. (2015). Free and Compulsory School Age Requirements. The Education Commission of the States.

Bound, J. and Freeman, R. B. (1992). What Went Wrong? The Erosion of Relative Earnings and Employment Among Young Black Men in the 1980s. The Quarterly Journal of Economics, 107(1):201-232.

Bound, J., Jaeger, D. A., and Baker, R. M. (1995). Problems with Instrumental Variables Estimation when the Correlation Between the Instruments and the Endogenous Explanatory Variable is Weak. Journal of the American statistical association, 90(430):443-450. 
Bureau of Labor Statistics, U.S. Department of Labor. National Longitudinal Survey of Youth 1997 cohort, 1997-2013 (rounds 1-16). Produced by the National Opinion Research Center, the University of Chicago and distributed by the Center for Human Resource Research, The Ohio State University. Columbus, OH: 2015.

Bureau of Labor Statistics, U.S. Department of Labor, and National Institute for Child Health and Human Development. Children of the NLSY79, 1979-2014. Produced and distributed by the Center for Human Resourse Research, The Ohio State University. Columbus, OH: 2015.

Cameron, A. C., Gelbach, J. B., and Miller, D. L. (2011). Robust Inference with Multiway Clustering. Journal of Business 65 Economic Statistics, 29(2):238-249.

Cameron, S. V. and Heckman, J. J. (1993). The Nonequivalence of High School Equivalents. Journal of labor economics, 11(1, Part 1):1-47.

Eckstein, Z. and Wolpin, K. I. (1989). Dynamic Labour Force Participation of Married Women and Endogenous Work Experience. The Review of Economic Studies, 56(3):375390.

Haney, W., Madaus, G., Abrams, L., Wheelock, A., Miao, J., Gruia, I., and Gruia, I. (2004). The Education Pipeline in the United States, 1970-2000.

Hauser, R. M., Frederick, C. B., and Andrew, M. (2007). Grade Retention in the Age of Standards-Based Reform. Center for Demography and Ecology, University of Wisconsin.

Heubert, J. P. and Hauser, R. M. (1998). High Stakes: Testing for Tracking, Promotion, and Graduation. National Research Council Committee on Appropriate Test Use, National Academies Press.

Imbens, G. W. and Angrist, J. D. (1994). Identification and Estimation of Local Average Treatment Effects. Econometrica, 62(2):467-475. 
Kena, G., Hussar, W., McFarland, J., de Brey, C., Musu-Gillette, L., Wang, X., Zhang, J., Rathbun, A., Wilkinson-Flicker, S., Diliberti, M., et al. (2016). The Condition of Education 2016. NCES 2016-144. National Center for Education Statistics.

Kreitzer, A. E., Madaus, G. F., and Haney, W. (1989). Competency Testing and Dropouts.

Lochner, L. and Moretti, E. (2004). The Effect of Education on Crime: Evidence from Prison Inmates, Arrests, and Self-Reports. The American Economic Review, 94(1):155-189.

Mackey, P. E. and Duncan, T. G. (2013). Does Raising the State Compulsory School Attendance Age Achieve the Intended Outcomes.

Oreopoulos, P. (2006). Estimating Average and Local Average Treatment Effects of Education when Compulsory Schooling Laws Really Matter. The American Economic Review, 96(1):152-175.

Oreopoulos, P. (2007a). Do Dropouts Drop Out Too Soon? Wealth, Health and Happiness from Compulsory Schooling. Journal of public Economics, 91(11):2213-2229.

Oreopoulos, P. (2007b). Would More Compulsory Schooling Help Disadvantaged Youth? Evidence from Recent Changes to School-Leaving Laws. In The problems of disadvantaged youth: An economic perspective, pages 85-112. University of Chicago Press.

Planty, M., Hussar, W. J., and Snyder, T. D. (2009). Condition of Education 2009. Government Printing Office.

Sable, J., Gaviola, N., and Hoffman, L. (2007). Numbers and Rates of Public High School Dropouts: School Year 2004-05. First Look (NCES 2008-305). National Center for Education Statistics.

Shepard, L. A. and Smith, M. L. (1989). Flunking Grades: Research and Policies on Retention (New York, NY: Falmer). 
Table 1: Summary Statistics

\begin{tabular}{lcccc}
\hline \hline \multirow{2}{*}{ Panel A: Enrollment Changes and Repeating } & $(1)$ & $(2)$ & $(3)$ & $(4)$ \\
& Mean & St. Dev. & Min & Max \\
\hline \% Change 7th - 8th & -0.957 & 2.629 & -23.54 & 25.31 \\
\% Change 8th - 9th & 6.427 & 6.797 & -16.35 & 47.10 \\
\% Change 9th - 10th & -6.075 & 5.377 & -38.16 & 19.00 \\
\% Change 10th - 11th & -8.123 & 4.439 & -28.75 & 19.79 \\
\% Change 11th - 12th & -6.927 & 4.473 & -27.53 & 18.48 \\
CPS 9th Grade Rep. Rate (\%) & 3.651 & 6.882 & 0 & 100 \\
Heubert and Hauser (1998) Repeating Rate & 11.648 & 4.359 & 2.6 & 21.0 \\
MA 1995-2012 Repeating Rate & 7.533 & 0.747 & 5.7 & 8.5 \\
\hline Panel B: CNLSY & & & & \\
& Mean & St. Dev. & Min & Max \\
\hline Educational Attainment & 12.348 & 1.910 & 8 & 20 \\
Black & 0.341 & 0.474 & 0 & 1 \\
Female & 0.559 & 0.497 & 0 & 1 \\
Hispanic & 0.204 & 0.403 & 0 & 1 \\
9th Grade Repeaters & 0.051 & 0.219 & 0 & 1 \\
Compulsory Attendance (Years) & 10.946 & 1.248 & 9 & 12 \\
Age & 23.204 & 4.196 & 15 & 42 \\
\hline (Conting
\end{tabular}

(Continued on next page) 
Table 1: (Continued)

\begin{tabular}{lcccc}
\hline \hline & $(1)$ & $(2)$ & $(3)$ & $(4)$ \\
Panel C: NLSY97 & Mean & St. Dev. & Min & Max \\
\hline GED & 0.118 & 0.322 & 0 & 1 \\
HS Diploma & 0.466 & 0.499 & 0 & 1 \\
HS Dropout (no GED) & 0.0725 & 0.259 & 0 & 1 \\
Associate's Degree & 0.0960 & 0.295 & 0 & 1 \\
Bachelor's Degree & 0.248 & 0.432 & 0 & 1 \\
9th Grade Repeats & 0.0499 & 0.264 & 0 & 4 \\
Any Grade Repeats & 0.376 & 0.717 & 0 & 6 \\
Urban Status & 0.773 & 0.419 & 0 & 1 \\
Black & 0.211 & 0.408 & 0 & 1 \\
Hispanic & 0.195 & 0.396 & 0 & 1 \\
Female & 0.491 & 0.500 & 0 & 1 \\
Age & 23.02 & 5.549 & 14 & 34 \\
\hline Panel D: Minimum Dropout Age Frequency & & & & \\
& Freq. & & & \\
\hline 14 & 0.612 & & & \\
15 & 0.163 & & & \\
16 & 62.24 & & & \\
18 & 16.20 & & & \\
\hline \hline
\end{tabular}

Notes: Enrollment changes in Panel A include all states and years from the 1965-66 academic year to the 2013-14 academic year. Other rates are described in the text. Panels B and C include all individuals in the CNLSY and NLSY97, respectively, with valid educational attainment, state of residence, race, sex, and wage information. Individuals with educational attainment less than 8 are omitted. Additionally, individuals who never provide a valid grade repeating history are omitted. Panel D provides the frequencies of minimum dropout ages across all state-year pairs in the United States (omitting AK, HI, and DC) from 1965-2014. 
Table 2: Pairwise Correlations, Repeating Rate Estimates

\begin{tabular}{lccc}
\hline \hline & $(1)$ & $(2)$ & $(3)$ \\
& $\begin{array}{c}\text { \% Change } \\
\text { 8th-9th }\end{array}$ & $\begin{array}{c}\text { \% Change } \\
\text { 9th-10th }\end{array}$ & CPS \\
\hline NRC \& MA Rep. Rates & 0.262 & -0.392 & 0.084 \\
$p-$ value,$\rho=0$ & 0.0143 & 0.0002 & 0.4873 \\
\hline \hline
\end{tabular}

Notes: P-values are shown for $H_{0}: \rho=0$. The CPS correlation in column (3) has 24 fewer observations, due to the existence of some NRC repeating rates before the introduction of the CPS October supplement in 1976. 
Table 3: Repeating Rate Estimates and True Repeating Rates

\begin{tabular}{lcccc}
\hline \hline & \multicolumn{3}{c}{ NRC \& MA Repeating Rates } \\
\cline { 2 - 5 } & $(1)$ & $(2)$ & $(3)$ & $(4)$ \\
\hline 9th-10th & $-0.877^{* *}$ & & & $-0.635^{* *}$ \\
& $(0.0528)$ & & & $(0.156)$ \\
8th-9th & & & & \\
& & $0.889^{*}$ & & $0.214^{* * *}$ \\
& & $(0.0662)$ & & $(0.152)$ \\
CPS & & & & \\
& & & $1.31^{*}$ & $0.0166^{* * *}$ \\
$N$ & & & $(0.174)$ & $(0.164)$ \\
$R^{2}$ & 97 & 97 & 73 & 73 \\
\hline${ }^{*} p<0.10,{ }^{* *} p<0.05,{ }^{* * *} p<0.01$ & 0.44 & 0.79 \\
\hline
\end{tabular}

Notes: Significance stars test $H_{0}: \beta=1$ or $H_{0}: \beta=-1$ for the appropriate estimate. The CPS regressions in columns (3) and (4) have 24 fewer observations, due to the existence of some NRC repeating rates before the introduction of the CPS October supplement in 1976 . 
Table 4: CSL Effects on 9th Grade Retention

\begin{tabular}{|c|c|c|c|c|c|c|c|c|}
\hline & \multicolumn{4}{|c|}{ 8th-9th Change } & \multicolumn{4}{|c|}{ 9th-10th Change } \\
\hline & (1) & $(2)$ & $(3)$ & $(4)$ & $(5)$ & (6) & $(7)$ & $(8)$ \\
\hline Dropout Age & $\begin{array}{c}2.707^{* * *} \\
(0.202)\end{array}$ & $\begin{array}{l}0.361^{* *} \\
(0.158)\end{array}$ & $\begin{array}{c}2.844^{* * *} \\
(0.207)\end{array}$ & $\begin{array}{c}0.744^{* * *} \\
(0.203)\end{array}$ & $\begin{array}{c}-1.835^{* * *} \\
(0.144)\end{array}$ & $\begin{array}{c}0.451^{* * *} \\
(0.127)\end{array}$ & $\begin{array}{c}-1.927^{* * *} \\
(0.146)\end{array}$ & $\begin{array}{c}-0.696^{* * *} \\
(0.141)\end{array}$ \\
\hline State FE & & $\mathrm{Y}$ & & $\mathrm{Y}$ & & $\mathrm{Y}$ & & $\mathrm{Y}$ \\
\hline Year FE & & & Y & $\mathrm{Y}$ & & & Y & $\mathrm{Y}$ \\
\hline Observations & 2352 & 2352 & 2352 & 2352 & 2352 & 2352 & 2352 & 2352 \\
\hline
\end{tabular}

Robust standard errors in parentheses

${ }^{*} p<0.10,{ }^{* *} p<0.05,{ }^{* * *} p<0.01$

Notes: Data on enrollment changes are from the NCES Annual Reports Program Historical Tables and CCD. All specifications include dropout age as a continuous variable between 14 and 18. Regressions are robust to omitting state-year pairs with a minimum dropout age below age $16(<1 \%$ of all state-year pairs) and to inclusion of indicators for each level of minimum dropout age, 14 to 18 . 
Table 5: CSL Effects on Non-9th Grade Promotion

\begin{tabular}{cccc}
\hline \hline & $(1)$ & $(2)$ & $(3)$ \\
& \% Change & \% Change & \% Change \\
& 7th - 8th & 10th - 11th & 11th - 12th \\
\hline Dropout Age & 0.0987 & 0.0717 & 0.0898 \\
& $(0.0863)$ & $(0.107)$ & $(0.110)$ \\
\hline Observations & 2352 & 2352 & 2352 \\
\hline \hline
\end{tabular}

Robust standard errors in parentheses

${ }^{*} p<0.10,{ }^{* *} p<0.05,{ }^{* * *} p<0.01$

Notes: Data on enrollment changes are from the NCES Annual Reports Program Historical Tables and CCD. All specifications include dropout age as a continuous variable between 14 and 18 . 
Table 6: Compulsory Schooling Instruments with 9th Grade Repeating

\begin{tabular}{|c|c|c|c|c|}
\hline & \multicolumn{4}{|c|}{ Outcome $=\log$ (hourly wage $)$} \\
\hline & \multicolumn{2}{|c|}{ No Repeat Control } & \multicolumn{2}{|c|}{ With Repeat Control } \\
\hline & $\begin{array}{l}\text { OLS } \\
(1)\end{array}$ & $\begin{array}{c}\text { 2SLS } \\
(2)\end{array}$ & $\begin{array}{c}\text { OLS } \\
(3)\end{array}$ & $\begin{array}{c}\text { 2SLS } \\
(4)\end{array}$ \\
\hline \multicolumn{5}{|c|}{ Panel A: Compulsory Schooling Law Instruments } \\
\hline Ed. Attainment & $\begin{array}{l}0.0595^{* * *} \\
(0.00212)\end{array}$ & $\begin{array}{c}0.130^{* *} \\
(0.0535)\end{array}$ & $\begin{array}{l}0.0594^{* * *} \\
(0.00217)\end{array}$ & $\begin{array}{c}0.120^{*} \\
(0.0720)\end{array}$ \\
\hline 9th Repeater & & & $\begin{array}{r}-0.00558 \\
(0.0160)\end{array}$ & $\begin{array}{c}-0.0599 \\
(0.339)\end{array}$ \\
\hline$K-P$ F-statistic & & [3.414] & & [1.584] \\
\hline \multicolumn{5}{|c|}{ Panel B: Quarter $\times$ Year of Birth Instruments } \\
\hline Ed. Attainment & $\begin{array}{l}0.0640^{* * *} \\
(0.00211)\end{array}$ & $\begin{array}{c}0.116^{* * *} \\
(0.00704)\end{array}$ & $\begin{array}{l}0.0646^{* * *} \\
(0.00215)\end{array}$ & $\begin{array}{l}0.0841^{* * *} \\
(0.00888)\end{array}$ \\
\hline 9th Repeater & & & $\begin{array}{l}0.0328^{* *} \\
(0.0155)\end{array}$ & $\begin{array}{c}1.009^{* * *} \\
(0.165)\end{array}$ \\
\hline$K-P$ F-statistic & & {$[37.875]$} & & {$[2.773]$} \\
\hline \multicolumn{5}{|c|}{ Panel C: Quarter $\times$ Year of Birth and CSL Instruments } \\
\hline Ed. Attainment & $\begin{array}{l}0.0640^{* * *} \\
(0.00211)\end{array}$ & $\begin{array}{c}0.115^{* * *} \\
(0.00695)\end{array}$ & $\begin{array}{l}0.0646^{* * *} \\
(0.00215)\end{array}$ & $\begin{array}{l}0.0935^{* * *} \\
(0.00789)\end{array}$ \\
\hline 9th Repeater & & & $\begin{array}{l}0.0328^{* *} \\
(0.0155)\end{array}$ & $\begin{array}{c}0.793^{* * *} \\
(0.131)\end{array}$ \\
\hline$K-P$ F-statistic & & [36.986] & & [2.898] \\
\hline Observations & 7511 & 7511 & 7511 & 7511 \\
\hline
\end{tabular}

Robust errors in parentheses

${ }^{*} p<0.10,{ }^{* *} p<0.05,{ }^{* * *} p<0.01$

Notes: Data source is the CNLSY. All regressions include controls for sex, race, and state of residence at age 16. Estimates in Panel A control for year of birth. Year of birth is included in the set of instruments (along with quarter of birth) in Panels $\mathrm{B}$ and $\mathrm{C}$, and is not included in OLS estimates in Panels B and C. 
Table 7: Black-White Wage and Employment Gaps, Corrected for Repeating

\begin{tabular}{|c|c|c|c|c|}
\hline & \multicolumn{2}{|c|}{$2000-2005$} & \multicolumn{2}{|c|}{$2006-2011$} \\
\hline & $(1)$ & $(2)$ & $(3)$ & $(4)$ \\
\hline \multicolumn{5}{|c|}{ Panel A: Outcome $=\log ($ Wage $)$} \\
\hline Black & $\begin{array}{c}-0.208^{* * *} \\
(0.0281)\end{array}$ & $\begin{array}{c}-0.184^{* * *} \\
(0.0282)\end{array}$ & $\begin{array}{c}-0.214^{* * *} \\
(0.0181)\end{array}$ & $\begin{array}{c}-0.201^{* * *} \\
(0.0181)\end{array}$ \\
\hline \multicolumn{5}{|c|}{ Panel B: Outcome = Employment Status } \\
\hline Black & $\begin{array}{c}-0.0921^{* * *} \\
(0.00978)\end{array}$ & $\begin{array}{c}-0.0929^{* * *} \\
(0.00976)\end{array}$ & $\begin{array}{c}-0.0627^{* * *} \\
(0.00769)\end{array}$ & $\begin{array}{r}-0.0618^{* * *} \\
(0.00769)\end{array}$ \\
\hline $\begin{array}{l}\text { Account for } \\
\text { Repeating }\end{array}$ & $\mathrm{N}$ & Y & $\mathrm{N}$ & Y \\
\hline$N$ & 8463 & 8463 & 13229 & 13229 \\
\hline
\end{tabular}

Robust standard errors in parentheses

${ }^{*} p<0.10,{ }^{* *} p<0.05,{ }^{* * *} p<0.01$

Notes: Data source is the NLSY97. All regressions include controls for educational attainment and urban status. Experience in columns (1) and (3) is included as min(Age-Educational Attainment-6, Age-18). Experience in columns (2) and (4) is included as $\min$ (Age-Educational Attainment-Repeated Grades-6, Age-Repeated Grades-18). Individuals enrolled in school are dropped from these regressions, as well as women and non-white, non-black individuals. 
Table 8: Grade Repeating Rates by Educational Attainment

\begin{tabular}{lccccc}
\hline \hline & \multicolumn{5}{c}{ Repeating Rates in NLSY97 (\%) } \\
& Dropouts & GED & HS Grads & Associate's & Bachelor's \\
\hline 9th Grade & 16.4 & 18.4 & 1.3 & 1.5 & $<1$ \\
All Grades & 72.6 & 73.6 & 21.1 & 16.8 & 6.1 \\
\hline \hline
\end{tabular}

Notes: Grade repeating rates by educational attainment are shown. Many individuals repeated multiple grades in their academic careers; this is not displayed in this table, but is accounted for in my later analysis. 
Table 9: Wage and Labor Supply Returns to GED and HS Diploma, Corrected for Repeating

\begin{tabular}{|c|c|c|c|}
\hline & \multicolumn{3}{|c|}{ Experience Correction } \\
\hline & $\begin{array}{c}(1) \\
\text { None }\end{array}$ & $\begin{array}{c}(2) \\
\text { 9th Grade } \\
\text { Repeating }\end{array}$ & $\begin{array}{c}(3) \\
\text { Any Grade } \\
\text { Repeating }\end{array}$ \\
\hline \multicolumn{4}{|c|}{ Panel A: Outcome $=\log ($ Hourly Wage $)$} \\
\hline GED & $\begin{array}{c}-0.374^{* * *} \\
(0.0306)\end{array}$ & $\begin{array}{c}-0.361^{* * *} \\
(0.0315)\end{array}$ & $\begin{array}{c}-0.327^{* * *} \\
(0.0330)\end{array}$ \\
\hline Dropout & $\begin{array}{c}-0.436^{* * *} \\
(0.0379)\end{array}$ & $\begin{array}{c}-0.430^{* * *} \\
(0.0380)\end{array}$ & $\begin{array}{c}-0.393^{* * *} \\
(0.0396)\end{array}$ \\
\hline HS Grad & $\begin{array}{c}-0.139^{* * *} \\
(0.0193)\end{array}$ & $\begin{array}{c}-0.139^{* * *} \\
(0.0193)\end{array}$ & $\begin{array}{c}-0.135^{* * *} \\
(0.0193)\end{array}$ \\
\hline $\begin{array}{l}\text { Chow Test } \chi^{2}: G E D=(1) \\
\text { Chow Test } \chi^{2}: G E D=(2)\end{array}$ & & 1.41 & $\begin{array}{l}11.68^{* * *} \\
5.51^{* *}\end{array}$ \\
\hline \multicolumn{4}{|c|}{ Panel B: Outcome $=\log ($ Annual Hours Worked $)$} \\
\hline GED & $\begin{array}{c}-0.162^{* * *} \\
(0.0240)\end{array}$ & $\begin{array}{r}-0.134^{* * *} \\
(0.0247)\end{array}$ & $\begin{array}{c}-0.121^{* * *} \\
(0.0259)\end{array}$ \\
\hline Dropout & $\begin{array}{c}-0.204^{* * *} \\
(0.0297)\end{array}$ & $\begin{array}{c}-0.190^{* * *} \\
(0.0298)\end{array}$ & $\begin{array}{c}-0.166^{* * *} \\
(0.0311)\end{array}$ \\
\hline HS Grad & $\begin{array}{l}-0.0259^{*} \\
(0.0152)\end{array}$ & $\begin{array}{l}-0.0260^{*} \\
(0.0151)\end{array}$ & $\begin{array}{l}-0.0218 \\
(0.0152)\end{array}$ \\
\hline $\begin{array}{l}\text { Chow Test } \chi^{2}: G E D=(1) \\
\text { Chow Test } \chi^{2}: G E D=(2)\end{array}$ & & $8.75^{* * *}$ & $\begin{array}{l}12.74^{* * *} \\
1.01\end{array}$ \\
\hline$N$ & 7956 & 7956 & 7956 \\
\hline
\end{tabular}

Robust standard errors in parentheses

${ }^{*} p<0.10,{ }^{* *} p<0.05,{ }^{* * *} p<0.01$

Notes: Baseline educational attainment is a college diploma, as repeating rates are lowest (6\%) for college graduates - this makes each column comparable. All coefficient estimates should be interpreted as the return relative to a college diploma. 
Table 10: Black-White Wage and Employment Gaps, Experience and Age

\begin{tabular}{|c|c|c|c|c|c|c|}
\hline & \multicolumn{3}{|c|}{$2000-2005$} & \multicolumn{3}{|c|}{ 2006-2011 } \\
\hline & $(1)$ & $(2)$ & $(3)$ & $(4)$ & $(5)$ & $(6)$ \\
\hline \multicolumn{7}{|c|}{ Panel A: Outcome $=\log ($ Wage $)$} \\
\hline Black & $\begin{array}{c}-0.198^{* * *} \\
(0.0279)\end{array}$ & $\begin{array}{c}-0.200^{* * *} \\
(0.0279)\end{array}$ & $\begin{array}{c}-0.175^{* * *} \\
(0.0279)\end{array}$ & $\begin{array}{c}-0.210^{* * *} \\
(0.0187)\end{array}$ & $\begin{array}{c}-0.209^{* * *} \\
(0.0187)\end{array}$ & $\begin{array}{c}-0.197^{* * *} \\
(0.0187)\end{array}$ \\
\hline \multicolumn{7}{|c|}{ Panel B: Outcome = Employment Status } \\
\hline Black & $\begin{array}{l}-0.104^{* * *} \\
(0.00948)\end{array}$ & $\begin{array}{l}-0.104^{* * *} \\
(0.00948) \\
\end{array}$ & $\begin{array}{c}-0.104^{* * *} \\
(0.00947) \\
\end{array}$ & $\begin{array}{c}-0.0539^{* * *} \\
(0.00799) \\
\end{array}$ & $\begin{array}{c}-0.0540^{* * *} \\
(0.00799) \\
\end{array}$ & $\begin{array}{c}-0.0531^{* * *} \\
(0.00800) \\
\end{array}$ \\
\hline Experience Control & Standard & Age & Std. + Reps. & Standard & Age & Std. + Reps. \\
\hline$N$ & 9003 & 9003 & 9003 & 12240 & 12240 & 12240 \\
\hline
\end{tabular}

Robust standard errors in parentheses

${ }^{*} p<0.10,{ }^{* *} p<0.05,{ }^{* * *} p<0.01$

Notes: Data source is the NLSY97. All regressions include controls for educational attainment and urban status. Experience in columns (1) and (4) is included as Age-Educational Attainment-6. Column (2) controls for Age instead of Experience. Experience in columns (3) and (6) is included as Age-Educational Attainment-Repeated Grades-6. Individuals enrolled in school are dropped from these regressions, as well as women and non-white, non-black individuals. 
Table 11: Wage and Labor Supply Returns to GED and HS Diploma, Experience and Age

\begin{tabular}{|c|c|c|c|}
\hline & \multicolumn{3}{|c|}{ Experience Control } \\
\hline & $\begin{array}{c}(1) \\
\text { Standard }\end{array}$ & $\begin{array}{l}(2) \\
\text { Age }\end{array}$ & $\begin{array}{c}(3) \\
\text { Standard } \\
+ \text { Reps. }\end{array}$ \\
\hline \multicolumn{4}{|c|}{ Panel A: Outcome $=\log ($ Hourly Wage $)$} \\
\hline GED & $\begin{array}{c}-0.374^{* * *} \\
(0.0306)\end{array}$ & $\begin{array}{c}-0.300^{* * *} \\
(0.0285)\end{array}$ & $\begin{array}{c}-0.327^{* * *} \\
(0.0330)\end{array}$ \\
\hline Dropout & $\begin{array}{r}-0.436^{* * *} \\
(0.0379)\end{array}$ & $\begin{array}{r}-0.349^{* * *} \\
(0.0357)\end{array}$ & $\begin{array}{r}-0.393^{* * *} \\
(0.0396)\end{array}$ \\
\hline HS Grad & $\begin{array}{c}-0.139^{* * *} \\
(0.0193)\end{array}$ & $\begin{array}{r}-0.140^{* * *} \\
(0.0193)\end{array}$ & $\begin{array}{r}-0.135^{* * *} \\
(0.0193)\end{array}$ \\
\hline $\begin{array}{l}\text { Chow Test } \chi^{2}: G E D=(1) \\
\text { Chow Test } \chi^{2}: G E D=(2)\end{array}$ & & $44.00^{* * *}$ & $\begin{array}{l}11.68^{* * *} \\
2.37\end{array}$ \\
\hline \multicolumn{4}{|c|}{ Panel B: Outcome $=\log ($ Annual Hours Worked $)$} \\
\hline GED & $\begin{array}{c}-0.162^{* * *} \\
(0.0240)\end{array}$ & $\begin{array}{r}-0.128^{* * *} \\
(0.0224)\end{array}$ & $\begin{array}{r}-0.121^{* * *} \\
(0.0259)\end{array}$ \\
\hline Dropout & $\begin{array}{c}-0.204^{* * *} \\
(0.0297)\end{array}$ & $\begin{array}{c}-0.164^{* * *} \\
(0.0281)\end{array}$ & $\begin{array}{c}-0.166^{* * *} \\
(0.0311)\end{array}$ \\
\hline HS Grad & $\begin{array}{l}-0.0259^{*} \\
(0.0152)\end{array}$ & $\begin{array}{l}-0.0263^{*} \\
(0.0151)\end{array}$ & $\begin{array}{l}-0.0218 \\
(0.0152)\end{array}$ \\
\hline $\begin{array}{l}\text { Chow Test } \chi^{2}: G E D=(1) \\
\text { Chow Test } \chi^{2}: G E D=(2)\end{array}$ & & $14.24^{* * *}$ & $\begin{array}{l}12.74^{* * *} \\
0.22\end{array}$ \\
\hline$N$ & 7956 & 7956 & 7956 \\
\hline
\end{tabular}

Robust standard errors in parentheses

${ }^{*} p<0.10,{ }^{* *} p<0.05,{ }^{* * *} p<0.01$

Notes: Baseline educational attainment is a college diploma, as repeating rates are lowest (6\%) for college graduates - this makes each column comparable. All coefficient estimates should be interpreted as the return relative to a college diploma. Column (1) uses the conventional potential experience measure (Age-Educational Attainment-6) and is identical to column (1) of Table 9. Column (2) controls for age instead of experience. Column (3) accounts for repeated grades in the potential experience measure (Age-Educational Attainment-Repeated Grades-6) and controls for repeated grades; it is identical to column (3) of Table 9. 
Figure 1: US Total Enrollment by Grade, 1977 \& 2014 Graduation Cohorts

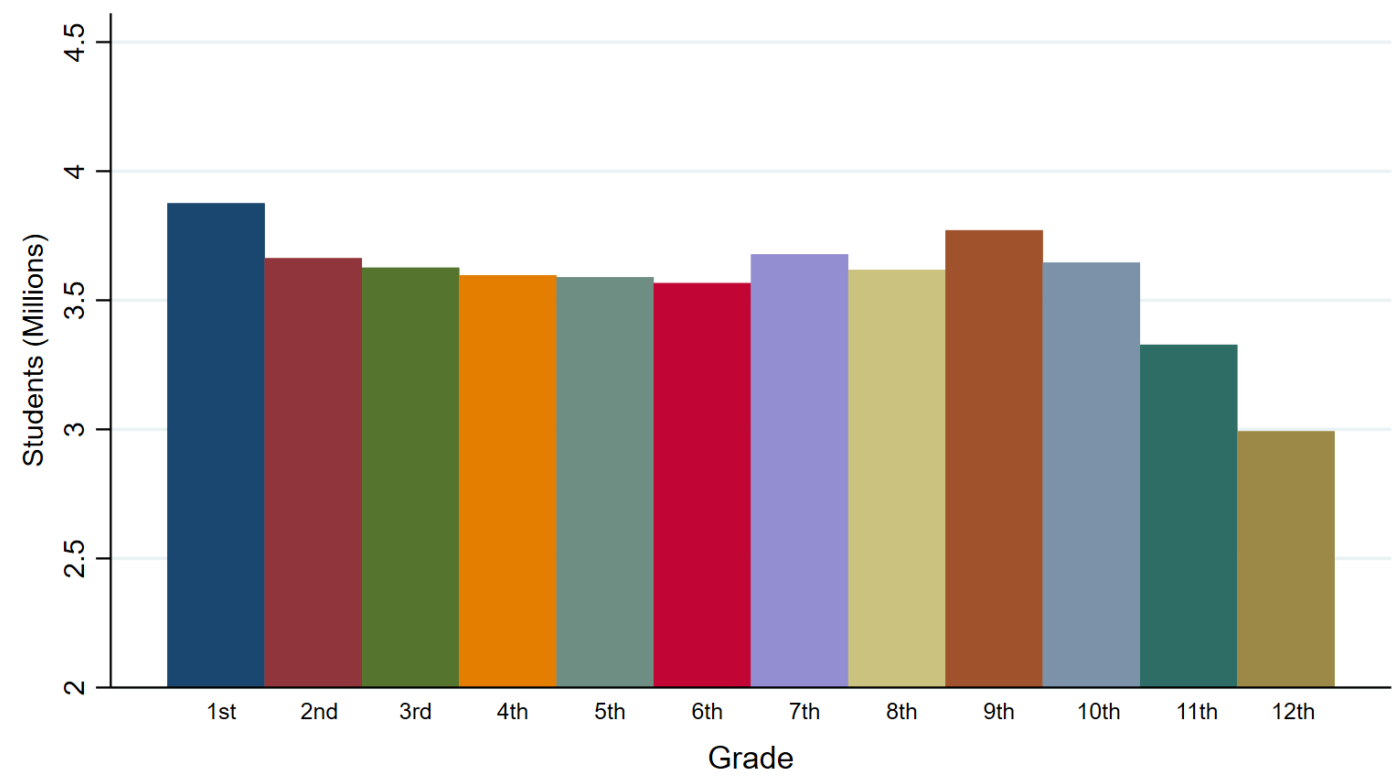

(a) 1977 Graduation Cohort

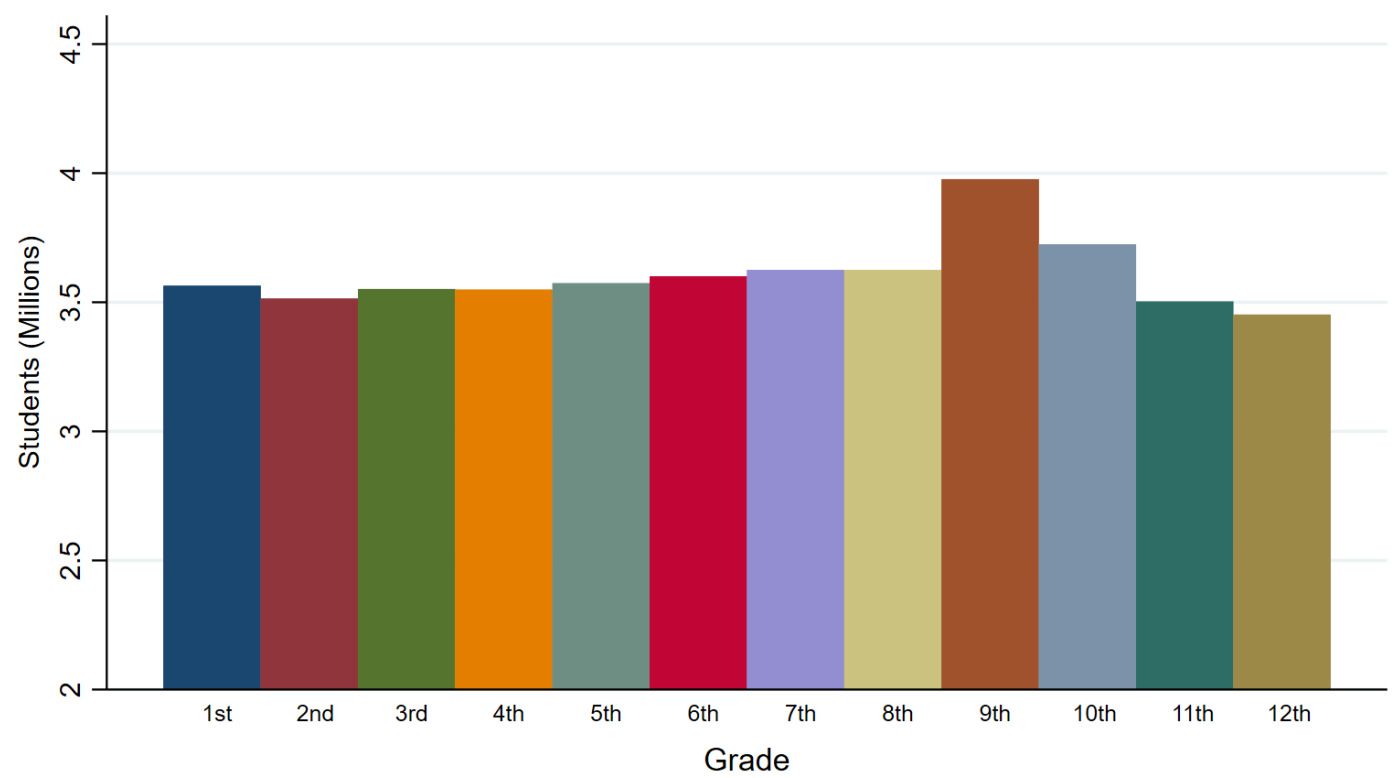

(b) 2014 Graduation Cohort

Notes: Enrollment data are from the NCES Annual Reports Historical Tables (a) and the NCES Common Core of Data (b). Both graphs show enrollment by projected graduation cohort. Graph (a) shows national 1st grade enrollment in the 1965-66 AY, 2nd grade enrollment in the 1966-67 AY, etc., ending with 12th grade enrollment in the 1976-77 AY. 
Figure 2: 9th Grade Repeating Rate Changes, 1965-2014

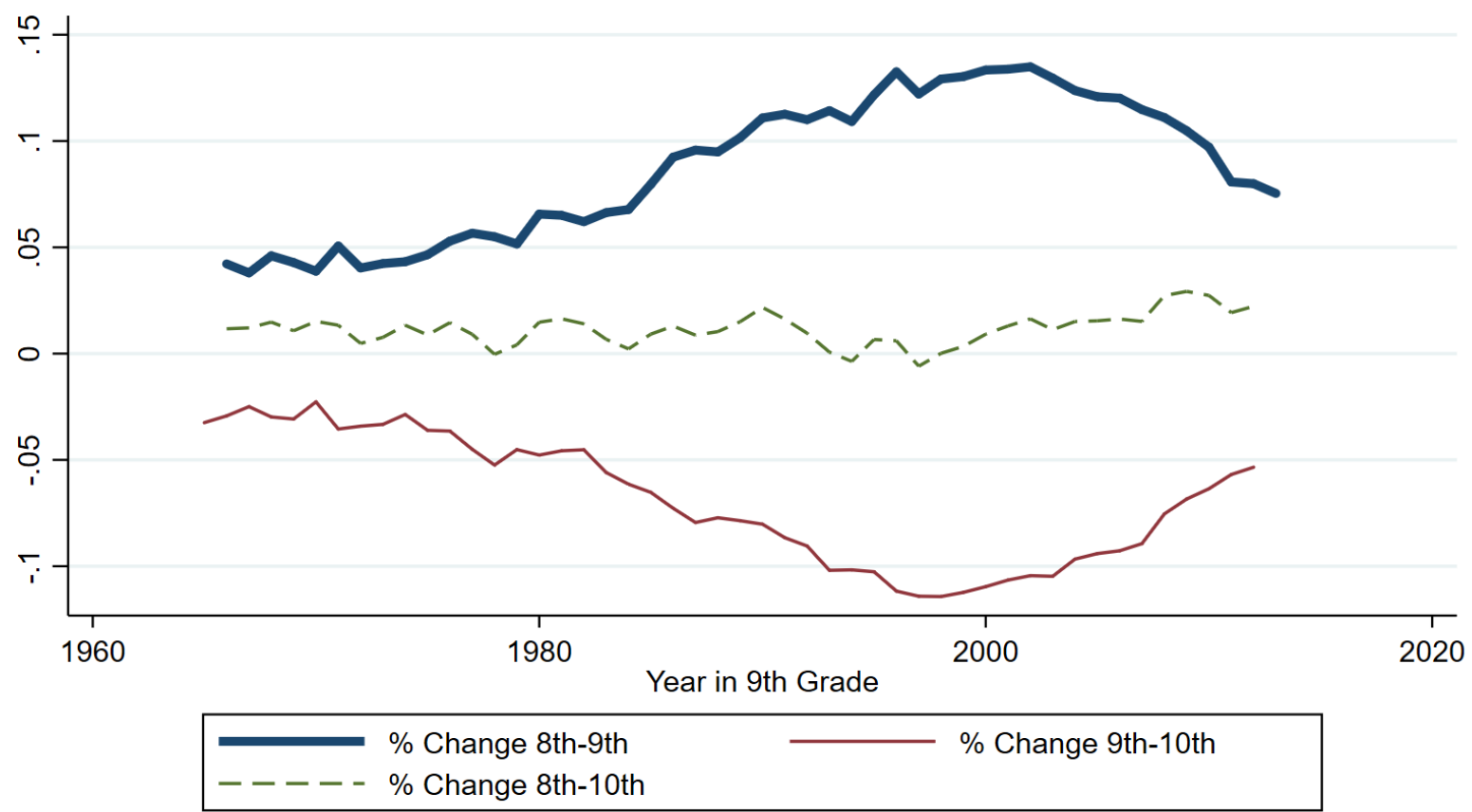

Notes: Enrollment data are from the NCES Annual Reports Historical Tables (1965-2003) and the NCES Common Core of Data (2004-2014). The "Year in 9th Grade" denotes in which October each cohort is enrolled in the 9th grade. All three lines are directly comparable at the cohort level; for year 1980, the \% Change 8th-9th shows the enrollment change between 8th grade in AY 1979-80 and 9th grade in AY 1980-81, the \% Change 9th-10th shows the enrollment change between 9th grade in AY 1980-81 and 10th grade in AY 1981-82, and the \% Change 8th-10th shows the enrollment change between 8th grade in AY 1979-80 and 10th grade in AY 1981-82. 
Figure 3: Minimum Dropout Age, 1965-2014

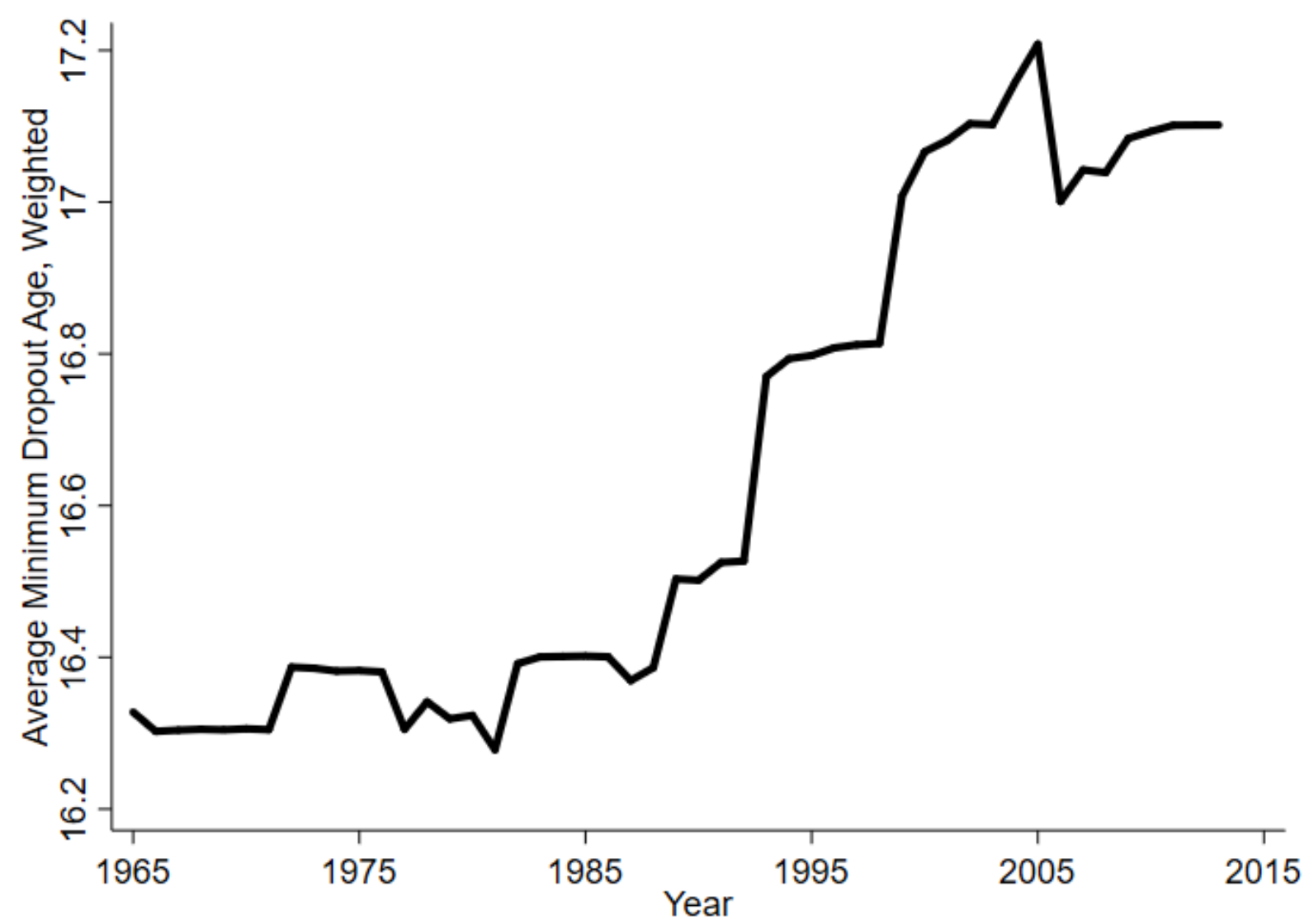

Notes: Average minimum dropout age, weighted by state high school enrollment (9th-12th grades) is shown from 1965-2014. Minimum dropout ages are taken from Oreopoulos (2006) for 1965-2005 and from Mackey and Duncan (2013) for 2005-2014. 
Figure 4: Event Study, CSL Effects on 9th Grade Retention

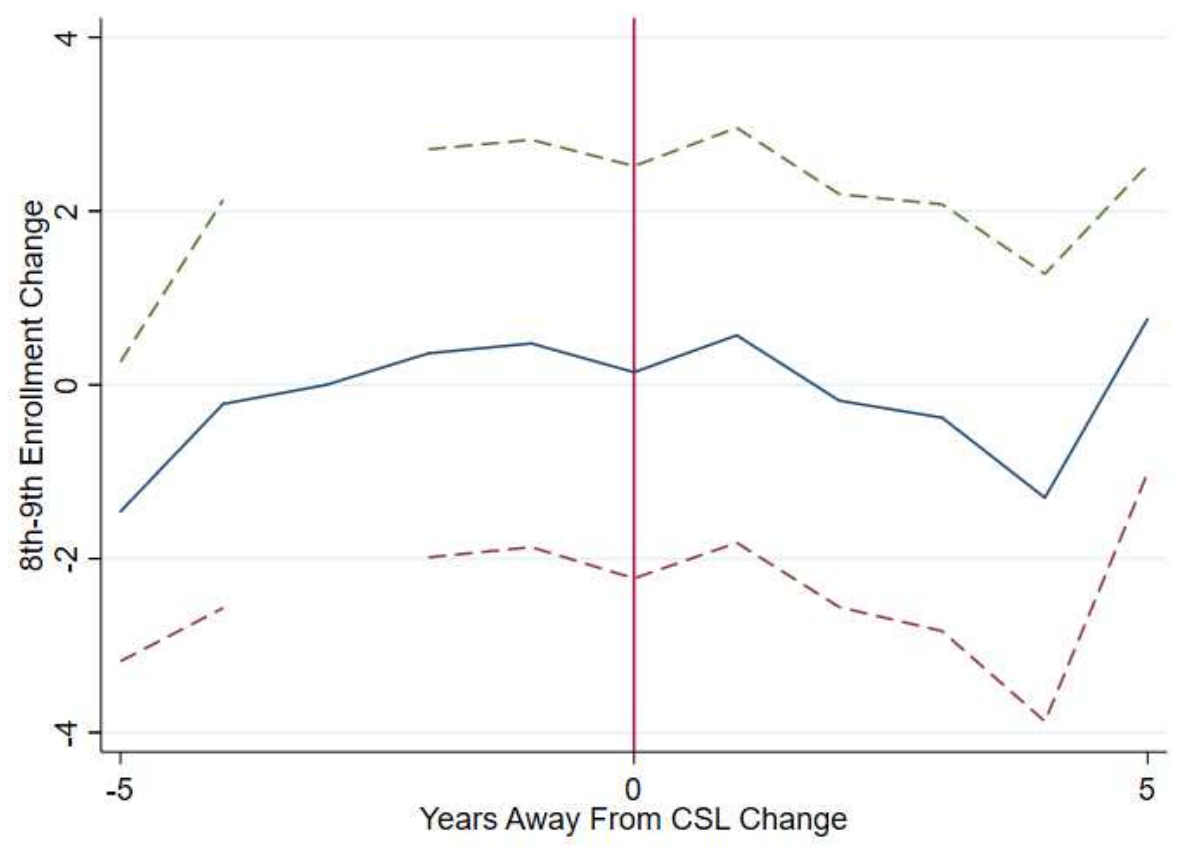

(a) \% Change 8th-9th

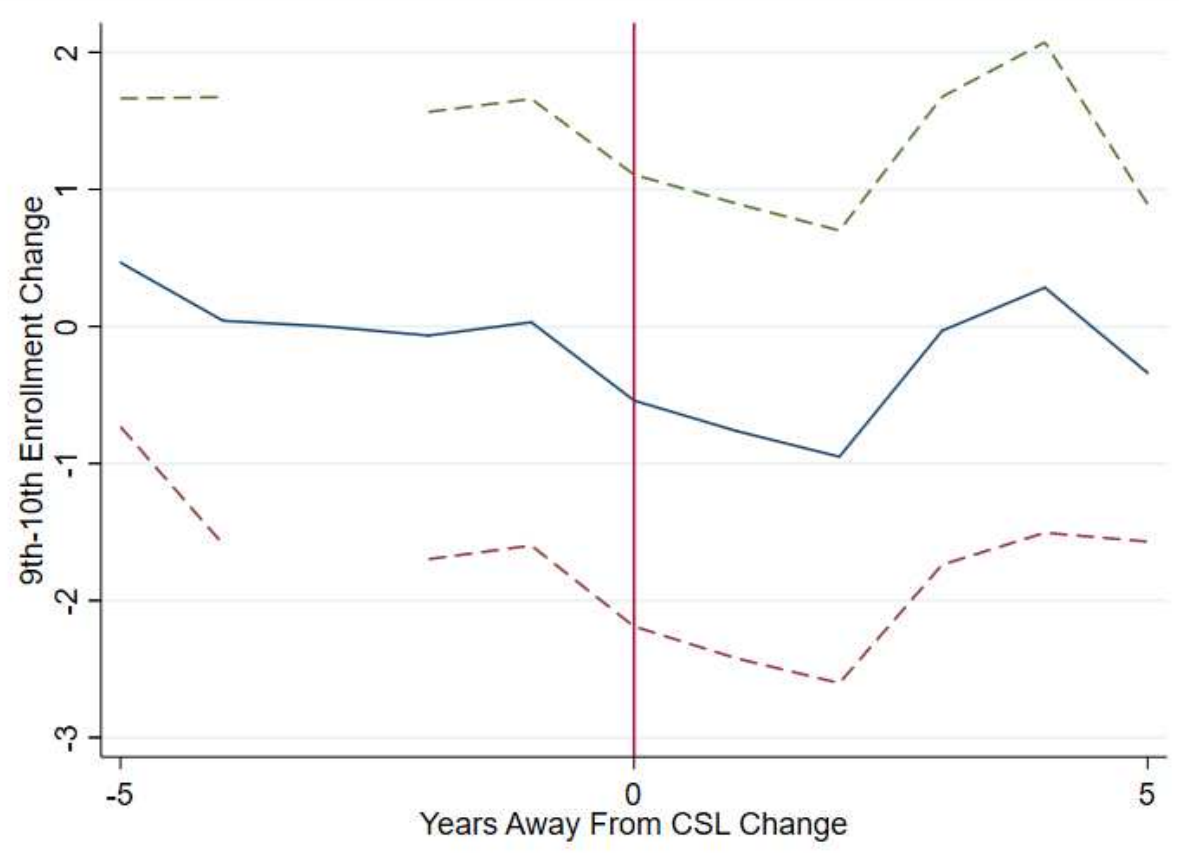

(b) \% Change 9th-10th

Notes: Both graphs show the coefficients from estimation of the dynamic difference-in-differences model in 7. Graph (a) shows coefficients with the enrollment change from 8th to 9th grade as the outcome variable, and graph (b) shows coefficients with the enrollment change from 9th to 10th grade as the outcome variable. The year that a minimum dropout age changes is denoted as $t=0$. States that change the minimum dropout age multiple times within 5 years are omitted in both figures. Coefficient estimates are relative to the baseline of 0 at $t=-3,3$ years before a minimum dropout age change. 
Appendix: Additional Tables and Figures 
Table A1: CSL Effects on 9th Grade Retention, Clustering

\begin{tabular}{ccccc}
\hline \hline & \multicolumn{4}{c}{ \% Change 9th - 10th } \\
\cline { 2 - 5 } & Robust & 2-Way Clustering, & 3-Way Clustering, \\
& 2 years per cluster & 3 years per cluster & State Clustering \\
\hline Dropout Age & $-0.696^{* * *}$ & $-0.696^{* * *}$ & $-0.696^{* *}$ & -0.696 \\
& $(0.141)$ & $(0.232)$ & $(0.278)$ & $(0.421)$ \\
\hline Observations & 2352 & 2352 & 2352 & 2352 \\
\hline \hline
\end{tabular}

Standard errors in parentheses

${ }^{*} p<0.10,{ }^{* *} p<0.05,{ }^{* * *} p<0.01$

Notes: $\quad N$-Way clustering in columns (2) and (3) refers to overlapping, but non-nested clustering over time horizons of size $N$ in a state as in Cameron et al. (2011). For example, 2-way clustering allows for serial correlation between consecutive years within a state, but does not allow for direct correlation between year $t$ and year $t+2$ in a state; year $t$ and $t+2$ are assumed to only be correlated through the pairwise correlations of $t$ and $t+1$, and $t+1$ and $t+2$. 
Table A2: Black-White Residual Wage Gap, Returns to Experience

\begin{tabular}{|c|c|c|c|c|}
\hline & \multicolumn{2}{|c|}{$2000-2005$} & \multicolumn{2}{|c|}{ 2006-2011 } \\
\hline Black & $\begin{array}{c}-0.208^{* * *} \\
(0.0281)\end{array}$ & $\begin{array}{c}-0.184^{* * *} \\
(0.0282)\end{array}$ & $\begin{array}{c}-0.214^{* * *} \\
(0.0181)\end{array}$ & $\begin{array}{r}-0.201^{* * *} \\
(0.0181)\end{array}$ \\
\hline Exp. $=1$ & $\begin{array}{l}0.204^{* * *} \\
(0.0487)\end{array}$ & $\begin{array}{l}0.203^{* * *} \\
(0.0419)\end{array}$ & $\begin{array}{c}0.0832 \\
(0.0767)\end{array}$ & $\begin{array}{c}0.0828 \\
(0.0743)\end{array}$ \\
\hline Exp. $=2$ & $\begin{array}{l}0.451^{* * *} \\
(0.0484)\end{array}$ & $\begin{array}{l}0.381^{* * *} \\
(0.0418)\end{array}$ & $\begin{array}{l}0.278^{* * *} \\
(0.0714)\end{array}$ & $\begin{array}{l}0.281^{* * *} \\
(0.0688)\end{array}$ \\
\hline Exp. $=3$ & $\begin{array}{l}0.601^{* * *} \\
(0.0497)\end{array}$ & $\begin{array}{l}0.558^{* * *} \\
(0.0434)\end{array}$ & $\begin{array}{l}0.453^{* * *} \\
(0.0696)\end{array}$ & $\begin{array}{l}0.444^{* * *} \\
(0.0671)\end{array}$ \\
\hline Exp. $=4$ & $\begin{array}{l}0.734^{* * *} \\
(0.0514)\end{array}$ & $\begin{array}{l}0.600^{* * *} \\
(0.0463)\end{array}$ & $\begin{array}{l}0.572^{* * *} \\
(0.0693)\end{array}$ & $\begin{array}{l}0.555^{* * *} \\
(0.0667)\end{array}$ \\
\hline Exp. $=5$ & $\begin{array}{l}0.738^{* * *} \\
(0.0561)\end{array}$ & $0.693^{* * *}$ & $\begin{array}{l}0.688^{* * *} \\
(0.0691)\end{array}$ & $\begin{array}{l}0.658^{* * *} \\
(0.0665)\end{array}$ \\
\hline Exp. $=6$ & $\begin{array}{l}0.776^{* * *} \\
(0.0629)\end{array}$ & $\begin{array}{l}0.740^{* * * *} \\
(0.0583)\end{array}$ & $\begin{array}{l}0.741^{* * *} \\
(0.0697)\end{array}$ & $\begin{array}{l}0.689^{* * *} \\
(0.0673)\end{array}$ \\
\hline Exp. $=7$ & $\begin{array}{l}0.869^{* * *} \\
(0.0761)\end{array}$ & $\begin{array}{l}0.800^{* * *} \\
(0.0974)\end{array}$ & $\begin{array}{l}0.800^{* * *} \\
(0.0701)\end{array}$ & $\begin{array}{l}0.760^{* * *} \\
(0.0676)\end{array}$ \\
\hline Exp. $=8$ & & & $\begin{array}{l}0.880^{* * *} \\
(0.0708)\end{array}$ & $\begin{array}{l}0.847^{* * *} \\
(0.0684)\end{array}$ \\
\hline Exp. $=9$ & & & $\begin{array}{l}0.917^{* * *} \\
(0.0715)\end{array}$ & $\begin{array}{l}0.851^{* * *} \\
(0.0696)\end{array}$ \\
\hline Exp. $=10$ & & & $\begin{array}{l}0.917^{* * *} \\
(0.0732)\end{array}$ & $\begin{array}{l}0.873^{* * *} \\
(0.0734)\end{array}$ \\
\hline $\begin{array}{l}\text { Account for } \\
\text { Repeating }\end{array}$ & $\mathrm{N}$ & $\mathrm{Y}$ & $\mathrm{N}$ & $\mathrm{Y}$ \\
\hline$N$ & 3874 & 3874 & 8430 & 8430 \\
\hline
\end{tabular}

Robust standard errors in parentheses

${ }^{*} p<0.10,{ }^{* *} p<0.05,{ }^{* * *} p<0.01$

Notes: Data source is the NLSY97. All regressions include controls for educational attainment and urban status. Experience in columns (1) and (3) is included as min(Age-Educational Attainment-6, Age-18). Experience in columns (2) and (4) is included as min(Age-Educational Attainment-Repeated Grades-6, Age-Repeated Grades-18). Individuals enrolled in school are dropped from these regressions, as well as women and non-white, non-black individuals. 
Table A3: Black-White Residual Employment Gap, Returns to Experience

\begin{tabular}{|c|c|c|c|c|}
\hline \multirow{3}{*}{ Black } & \multicolumn{4}{|c|}{ Outcome = Employment Status } \\
\hline & \multicolumn{2}{|c|}{$2000-2005$} & \multicolumn{2}{|c|}{ 2006-2011 } \\
\hline & $\begin{array}{c}-0.0921^{* * *} \\
(0.00978)\end{array}$ & $\begin{array}{c}-0.0929^{* * *} \\
(0.00976)\end{array}$ & $\begin{array}{c}-0.0627^{* * *} \\
(0.00769)\end{array}$ & $\begin{array}{c}-0.0618^{* * *} \\
(0.00769)\end{array}$ \\
\hline Exp. $=1$ & $\begin{array}{l}-0.0114 \\
(0.0155)\end{array}$ & $\begin{array}{l}-0.0169 \\
(0.0135)\end{array}$ & $\begin{array}{c}0.00366 \\
(0.0236)\end{array}$ & $\begin{array}{l}0.00459 \\
(0.0234)\end{array}$ \\
\hline Exp. $=2$ & $\begin{array}{r}-0.00568 \\
(0.0156)\end{array}$ & $\begin{array}{c}-0.0000431 \\
(0.0139)\end{array}$ & $\begin{array}{c}0.000762 \\
(0.0225)\end{array}$ & $\begin{array}{c}0.0166 \\
(0.0219)\end{array}$ \\
\hline Exp. $=3$ & $\begin{array}{l}-0.0185 \\
(0.0166)\end{array}$ & $\begin{array}{c}-0.0294^{*} \\
(0.0153)\end{array}$ & $\begin{array}{c}0.0216 \\
(0.0216)\end{array}$ & $\begin{array}{c}0.0272 \\
(0.0213)\end{array}$ \\
\hline Exp. $=4$ & $\begin{array}{c}-0.0321^{*} \\
(0.0182)\end{array}$ & $\begin{array}{c}-0.0340^{*} \\
(0.0174)\end{array}$ & $\begin{array}{l}0.00647 \\
(0.0215)\end{array}$ & $\begin{array}{l}0.0358^{*} \\
(0.0211)\end{array}$ \\
\hline Exp. $=5$ & $\begin{array}{l}-0.0214 \\
(0.0201)\end{array}$ & $\begin{array}{c}-0.0344^{*} \\
(0.0202)\end{array}$ & $\begin{array}{c}0.0301 \\
(0.0214)\end{array}$ & $\begin{array}{l}0.0399^{*} \\
(0.0211)\end{array}$ \\
\hline Exp. $=6$ & $\begin{array}{l}-0.0155 \\
(0.0237)\end{array}$ & $\begin{array}{c}-0.0515^{* *} \\
(0.0262)\end{array}$ & $\begin{array}{c}0.0294 \\
(0.0217)\end{array}$ & $\begin{array}{l}0.0486^{* *} \\
(0.0213)\end{array}$ \\
\hline Exp. $=7$ & $\begin{array}{c}0.000300 \\
(0.0327)\end{array}$ & $\begin{array}{c}0.0610^{*} \\
(0.0364)\end{array}$ & $\begin{array}{c}0.0376^{*} \\
(0.0220)\end{array}$ & $\begin{array}{l}0.0488^{* *} \\
(0.0217)\end{array}$ \\
\hline Exp. $=8$ & & & $\begin{array}{c}0.0327 \\
(0.0224)\end{array}$ & $\begin{array}{l}0.0534^{* *} \\
(0.0221)\end{array}$ \\
\hline Exp. $=9$ & & & $\begin{array}{c}0.0357 \\
(0.0230)\end{array}$ & $\begin{array}{l}0.0556^{* *} \\
(0.0231)\end{array}$ \\
\hline Exp. $=10$ & & & $\begin{array}{c}0.0331 \\
(0.0241)\end{array}$ & $\begin{array}{l}0.0572^{* *} \\
(0.0256)\end{array}$ \\
\hline $\begin{array}{l}\text { Account for } \\
\text { Repeating }\end{array}$ & $\mathrm{N}$ & Y & $\mathrm{N}$ & $\mathrm{Y}$ \\
\hline$N$ & 8463 & 8463 & 13229 & 13229 \\
\hline
\end{tabular}

Robust standard errors in parentheses

${ }^{*} p<0.10,{ }^{* *} p<0.05,{ }^{* * *} p<0.01$

Notes: Data source is the NLSY97. All regressions include controls for educational attainment and urban status. Experience in columns (1) and (3) is included as min(Age-Educational Attainment-6, Age-18). Experience in columns (2) and (4) is included as min(Age-Educational Attainment-Repeated Grades-6, Age-Repeated Grades-18). Individuals enrolled in school are dropped from these regressions, as well as women and non-white, non-black individuals. 